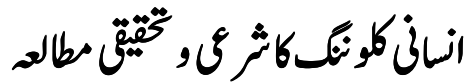 \\ A scholarly review of human cloning in the light of Islamic injunctions
}

Published:

31-12-2021

Accepted:

25-10-2021

Received:

25-09-2021
Waqas Ali Haider

PhD Scholar, Department of Islamic Studies,

University of Okara

Email:waqas.alihaider@gmail.com

Muhammad Aslam

PhD Scholar, Department of Islamic Studies, University of Okara

Email: aslamazad173@gmail.com

\section{Ayesha Irshad}

Lecturer Islamic Studies, Frontier group of colleges

Arifwala

Email: ayeshairshad63eb@gmail.com

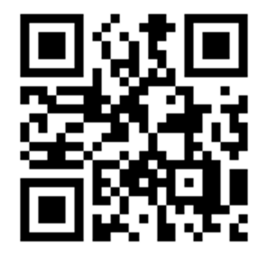

\section{Abstract}

This paper explores the diverse social, cultural and scientific facets of cloning as an alternate means of human reproduction. We review the various types, and implications of cloning as practiced in the modern world, specifically as a means of child birth for infertile parents. We also present the Islamic injunctions and worldview on different types of cloning. We assert that although biological cloning can be an productive technological intervention to promote agriculture yield, however its application for human reproduction is inappropriate, and finds no support in Islamic injunctions. Therefore, our paper suggest that human cloning should be prohibited acknowledging its socioeconomic demerits.

Keyword: Cloning, Islam, Human Reproduction, Figh, Medical Science

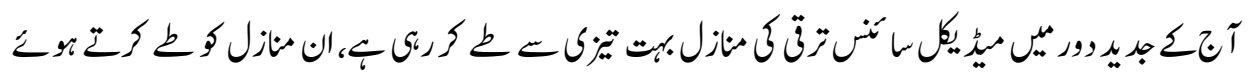

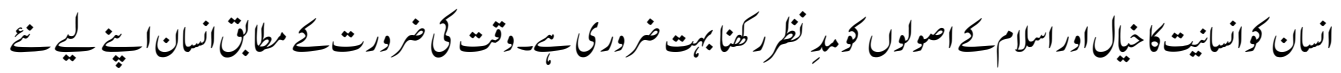

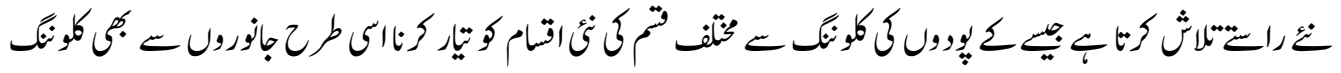

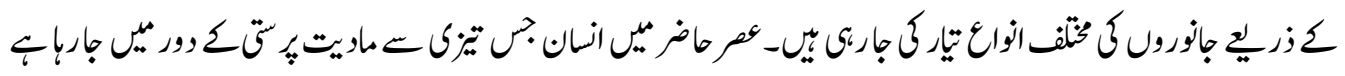

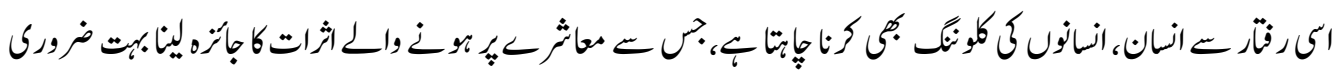




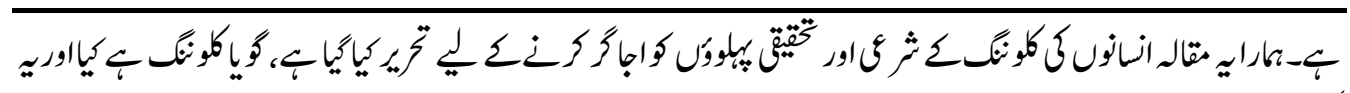

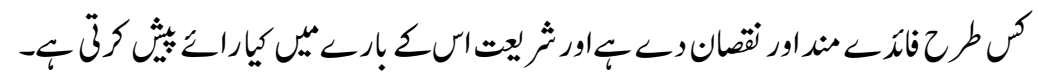
كلونكاتر ليف:

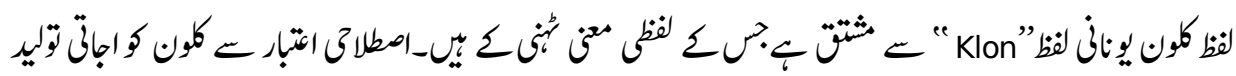
"! Vegetative Reproduction”

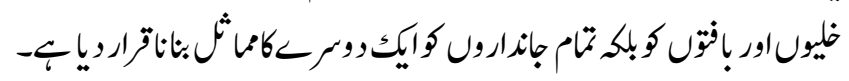

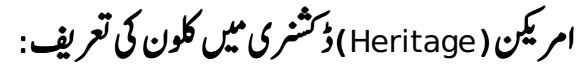

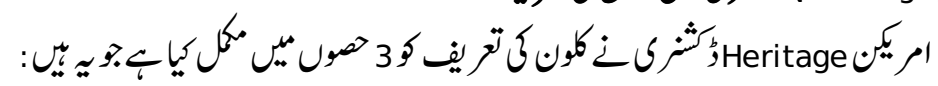

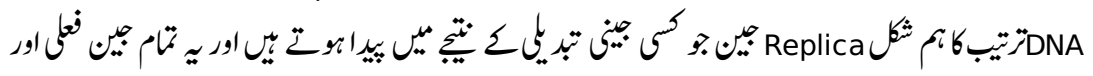

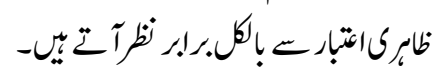

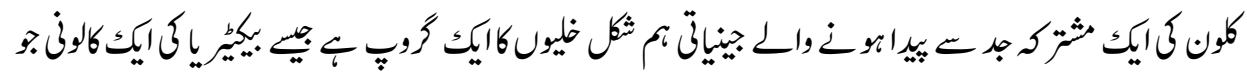

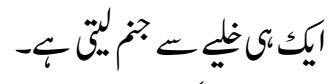

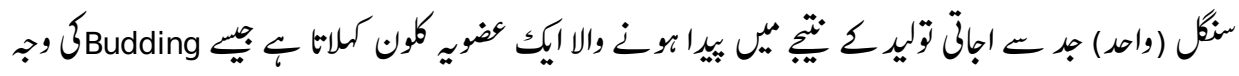

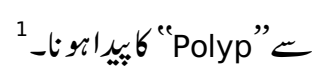
عAMA

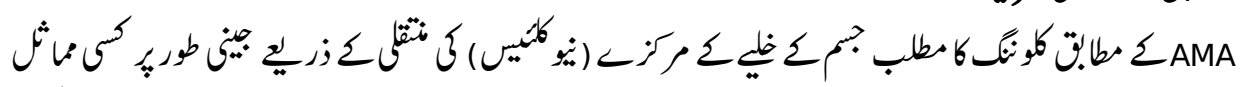

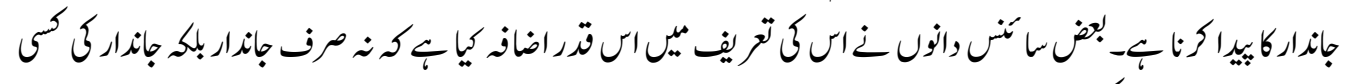

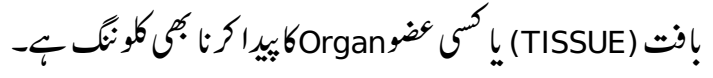

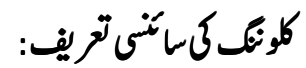

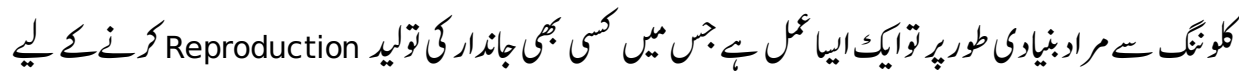

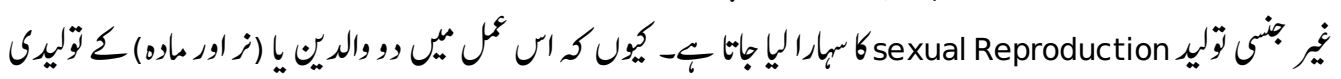

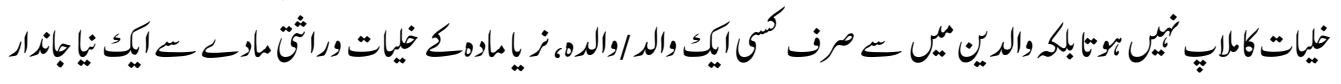
بيراتو جابتاب

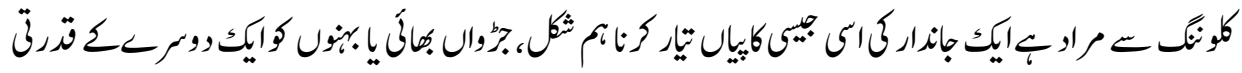

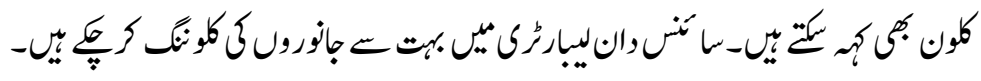

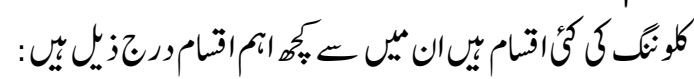
كلونك كاقام:

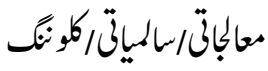




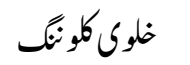

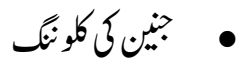

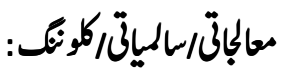

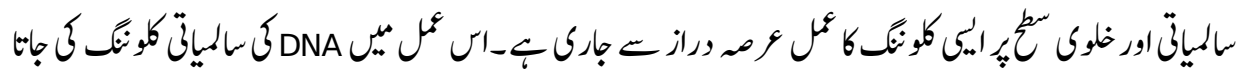

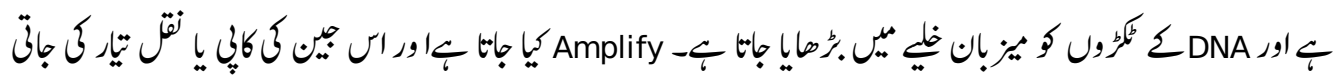

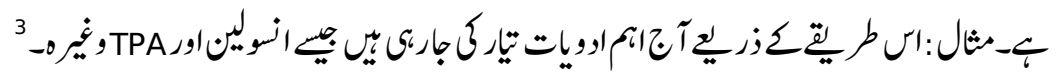

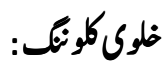

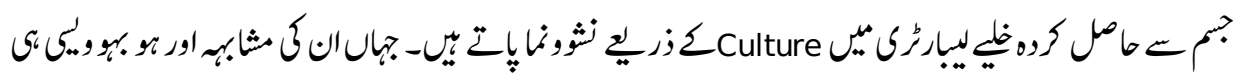

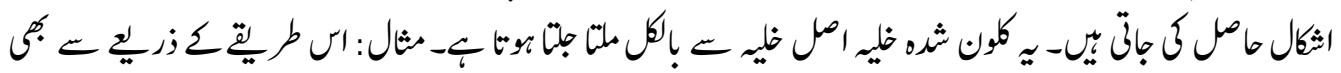

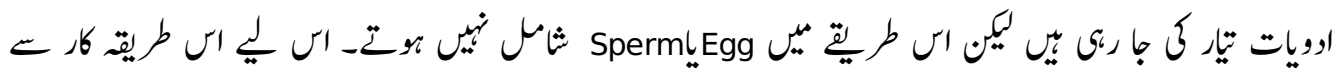
4.

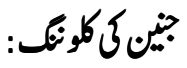

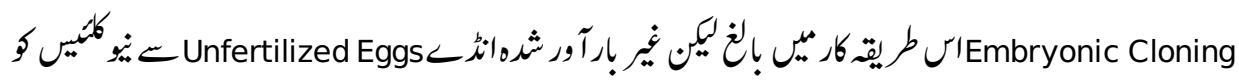

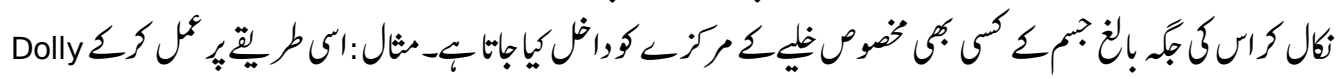

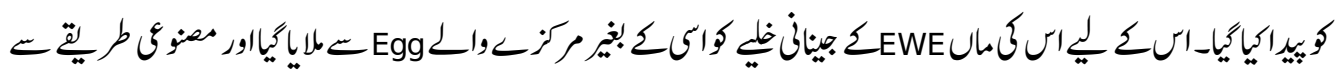

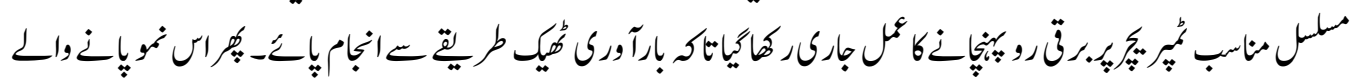

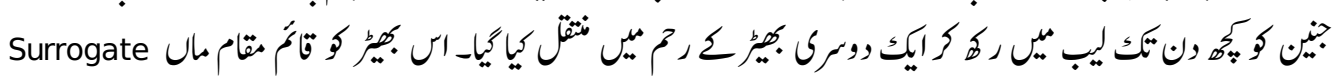
Mother

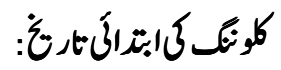

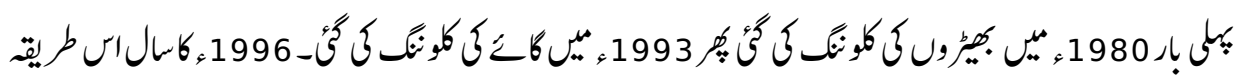

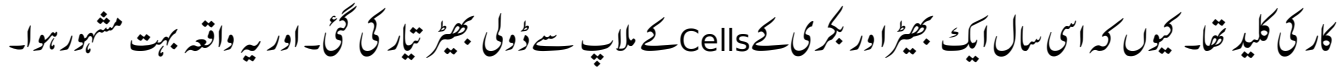

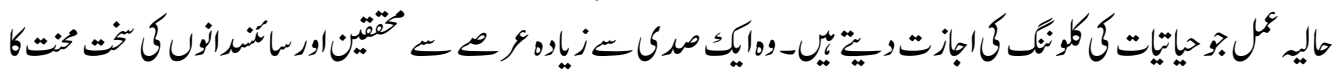

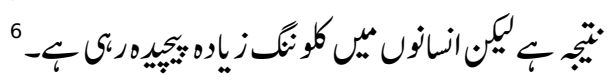

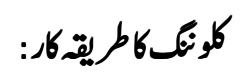

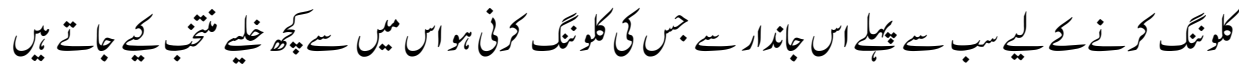

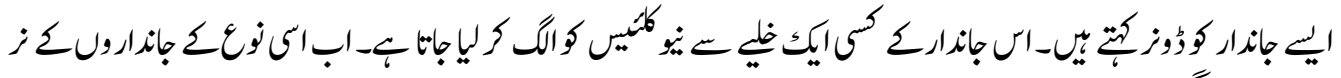

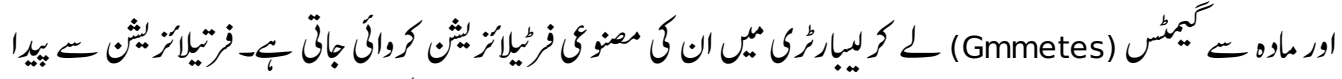

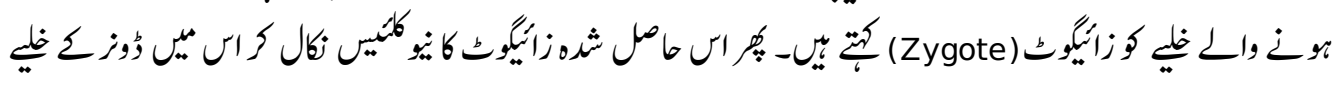




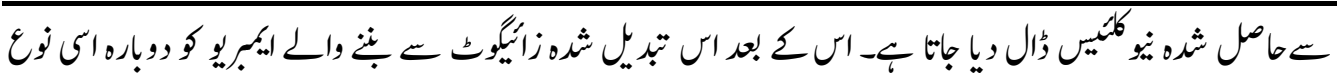

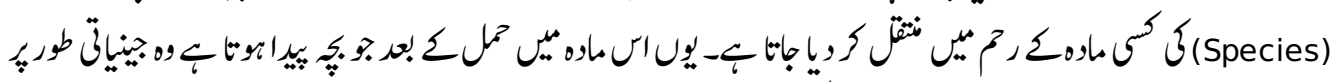

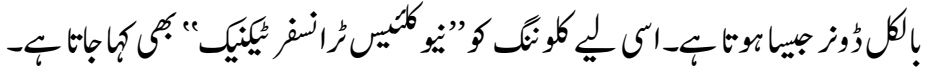

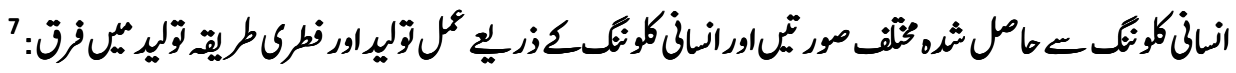

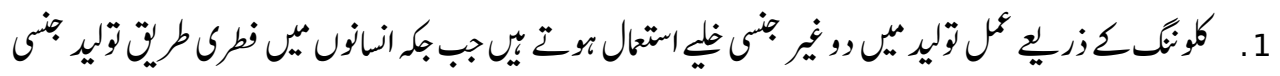

$$
\text { خليول كانوتاب }
$$

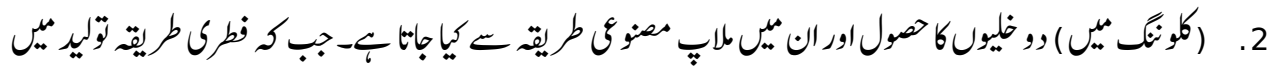

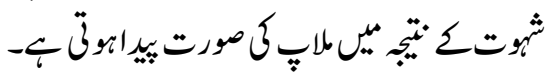

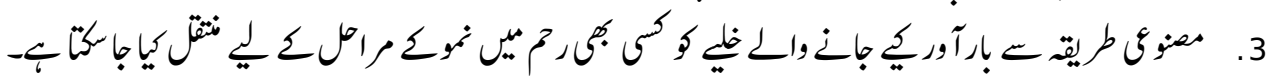

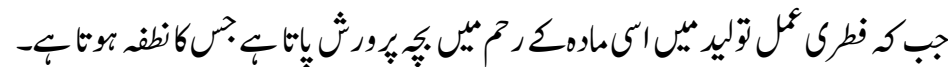

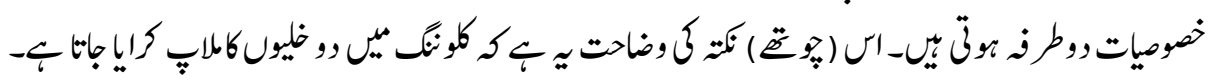

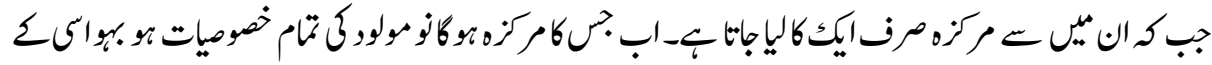

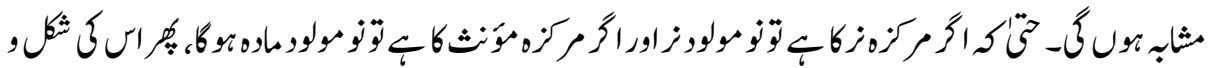

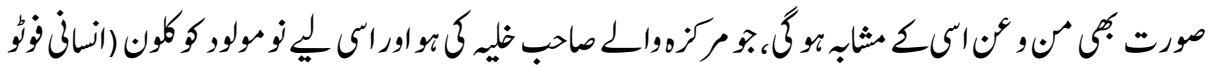

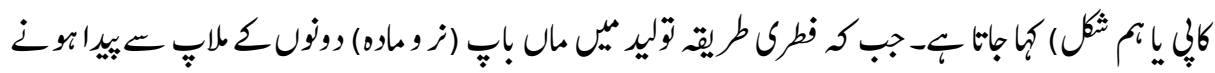

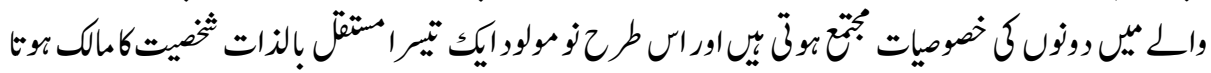

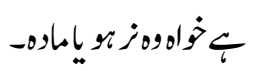

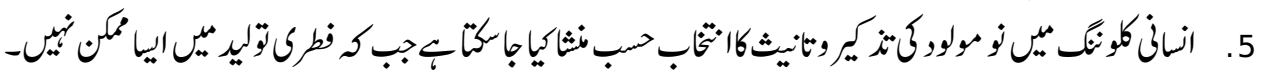

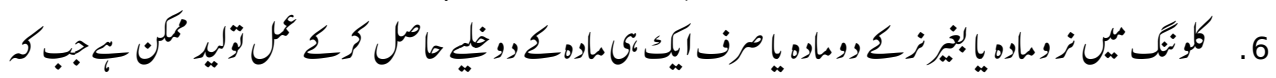

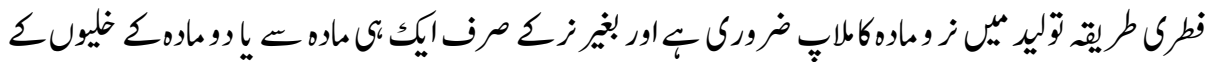

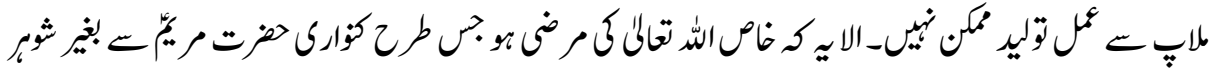

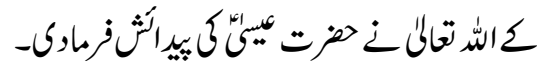

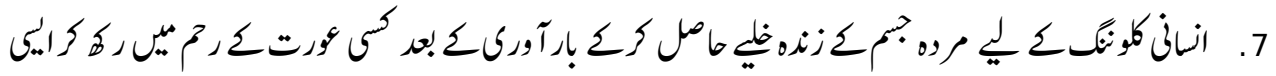

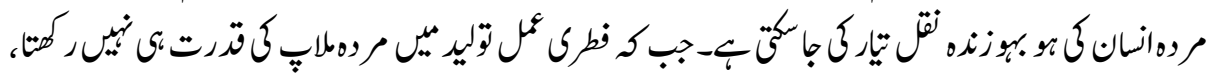

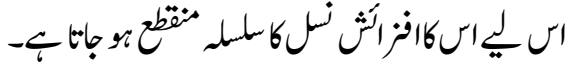

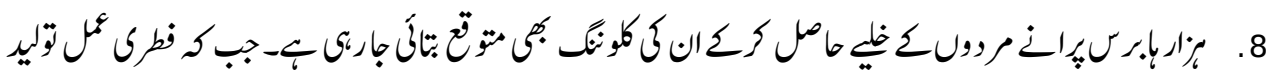

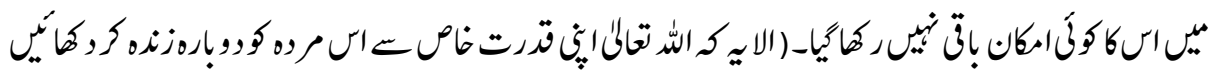




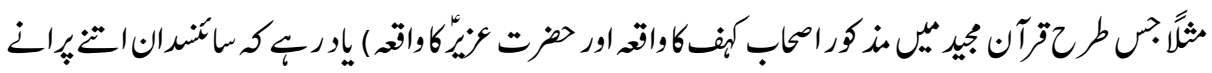

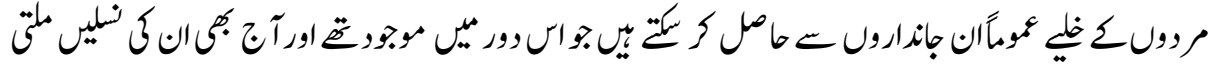

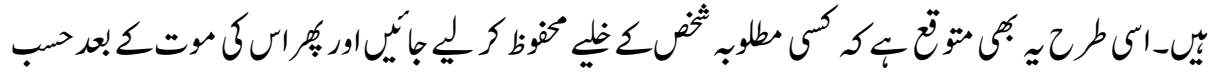

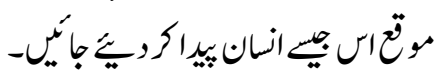

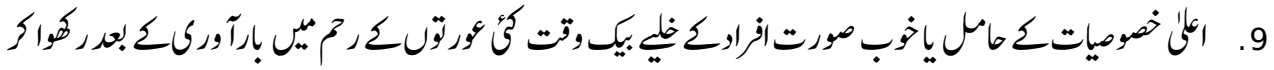

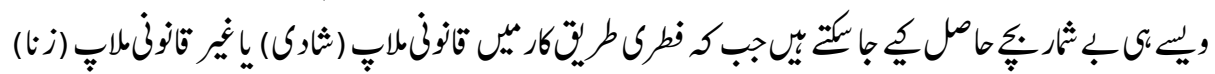

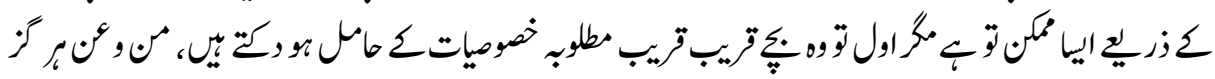

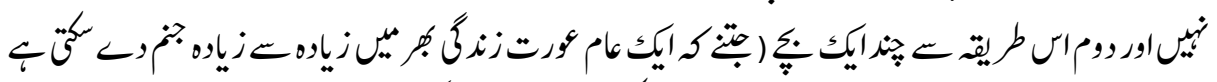

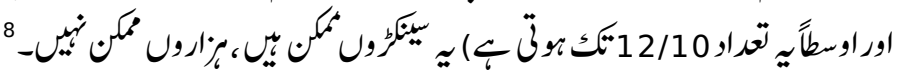

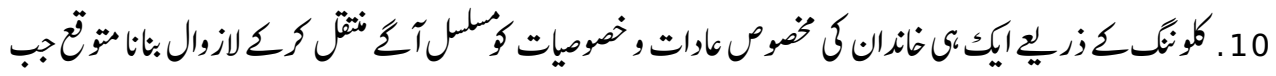

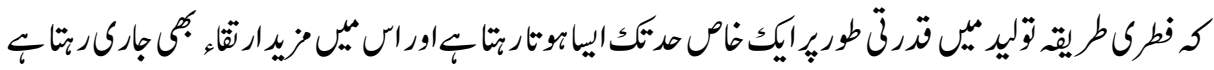

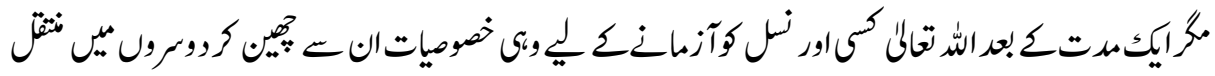

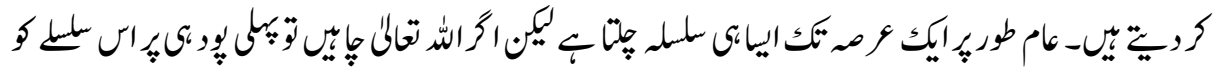

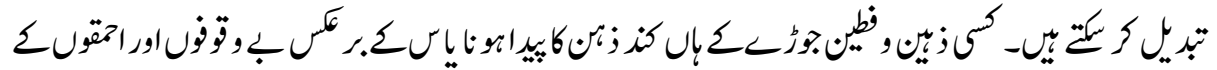

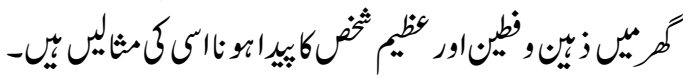

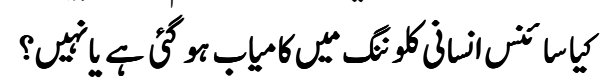

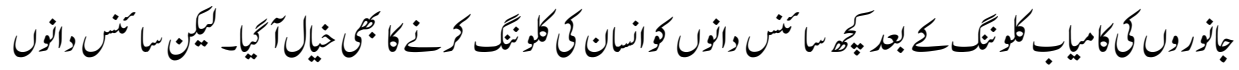

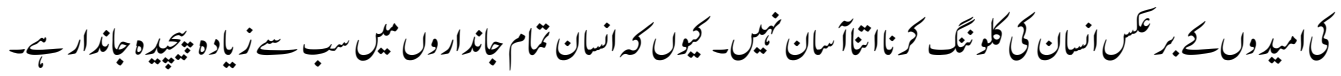

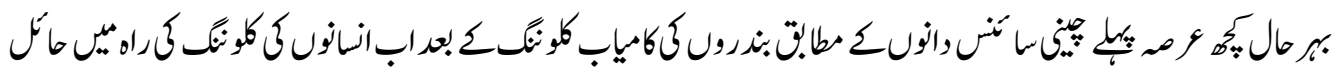
ركاوت

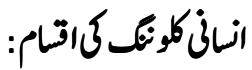

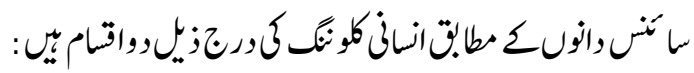
THERAPUTIC CLONING

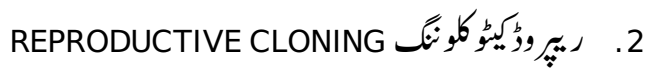

تيرابيوكك كلمنكس:

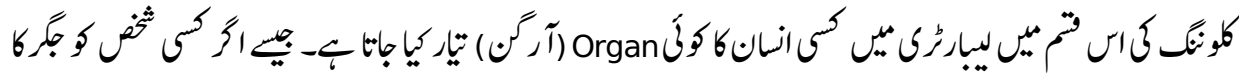

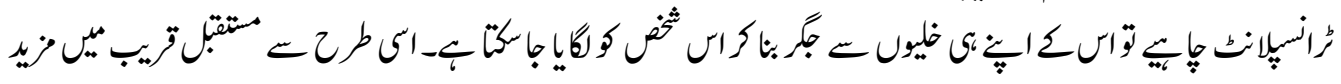

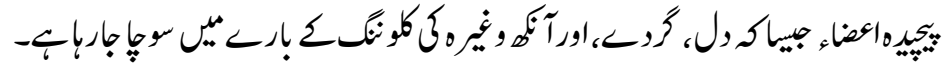




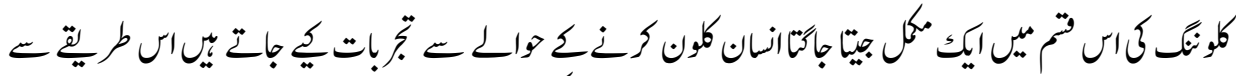

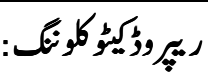

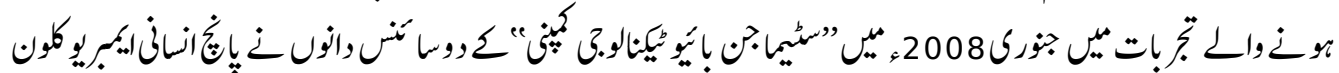

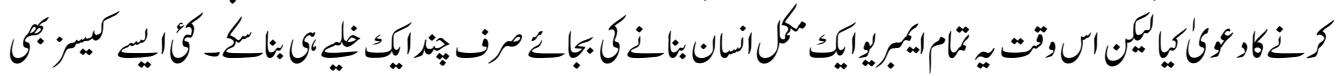

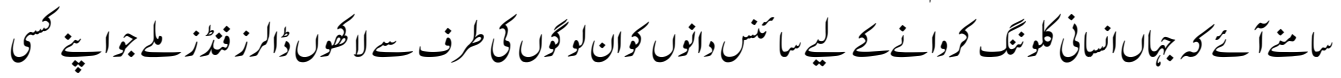

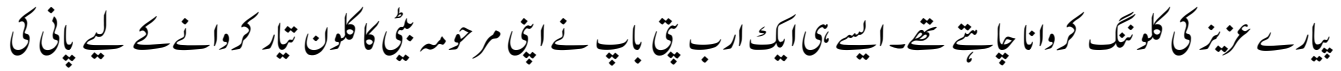

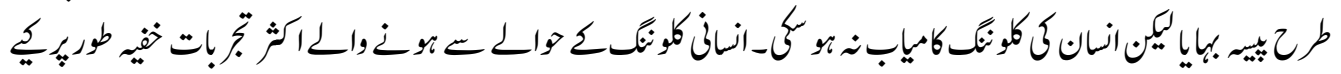

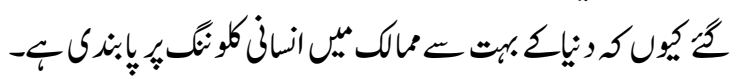

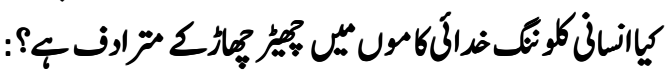

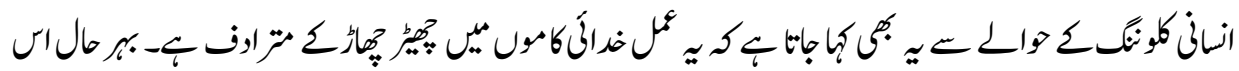

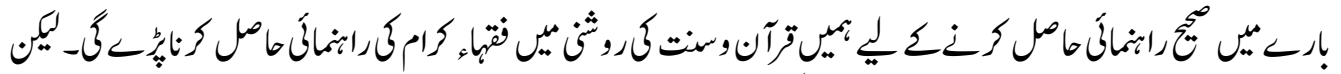

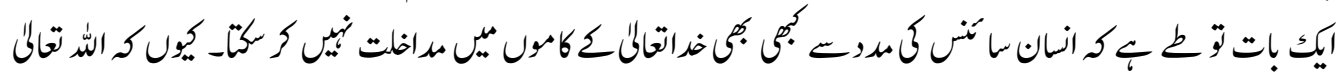

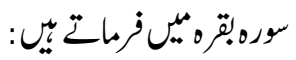

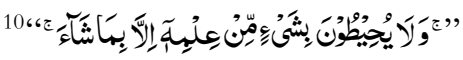

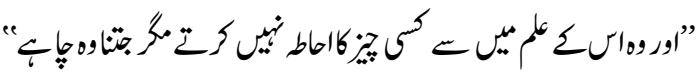

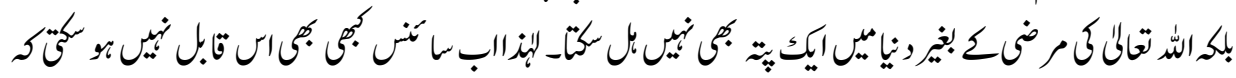

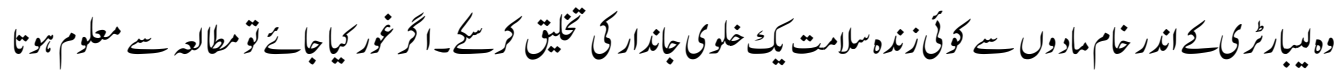

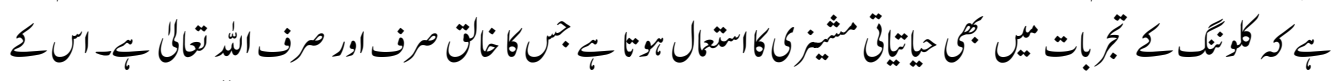

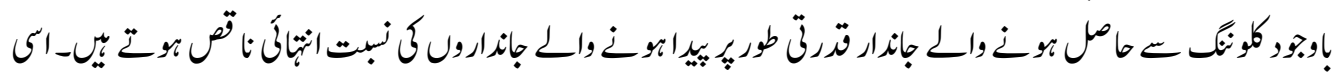

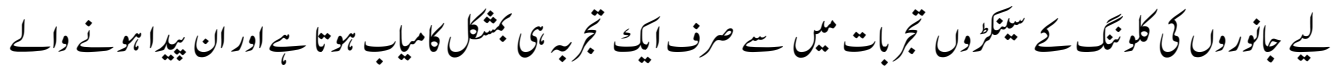

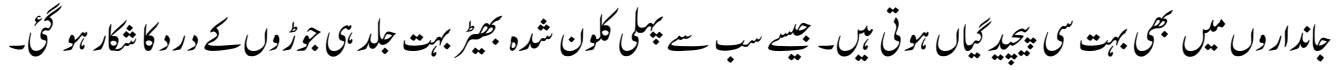

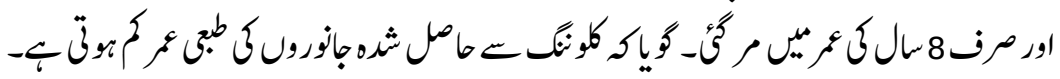

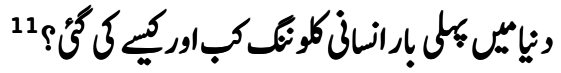

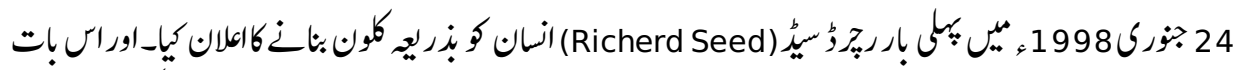

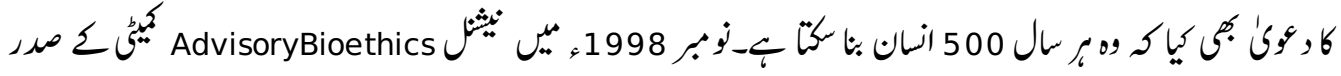

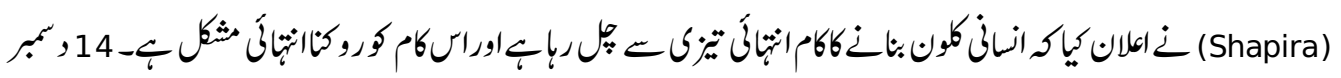

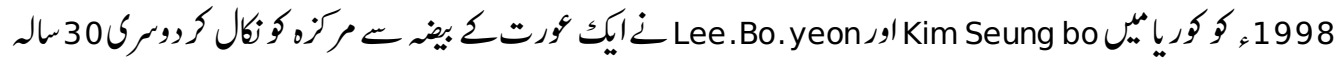

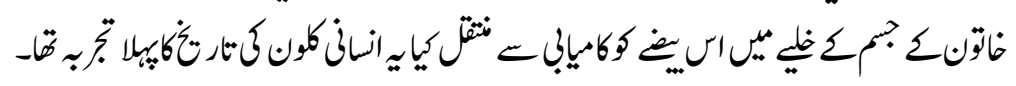




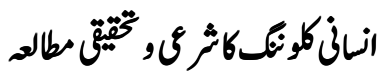

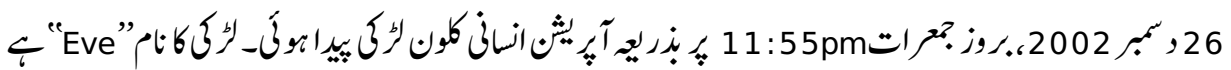

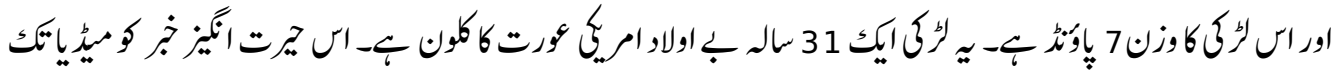
Clonaid

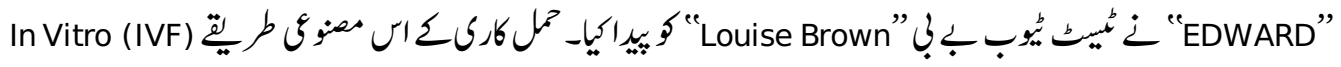

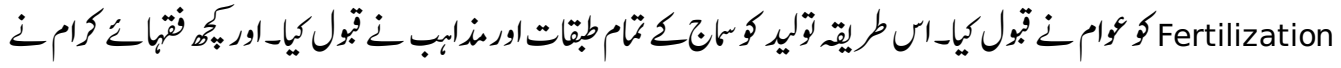

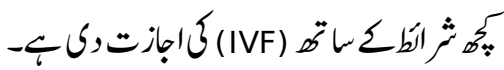

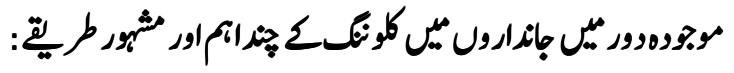

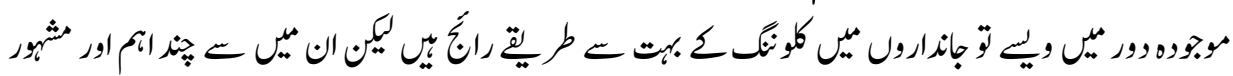

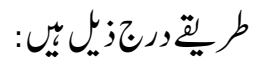

$$
\begin{aligned}
& \text { 1. } 1 \text { (SCNT) } \\
& \text { 2. } \\
& \text { اسئم =يليل: Pluripotent }
\end{aligned}
$$

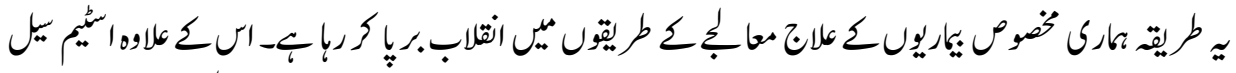

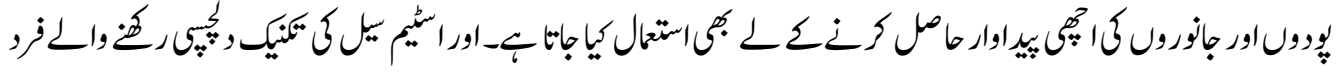

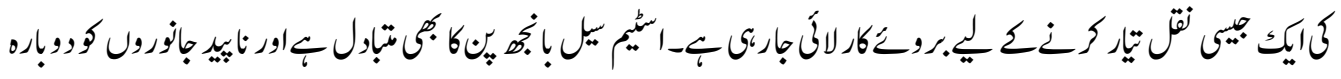

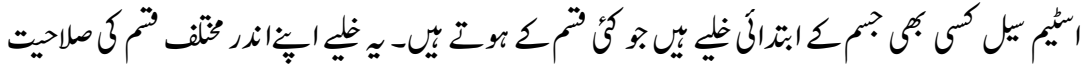

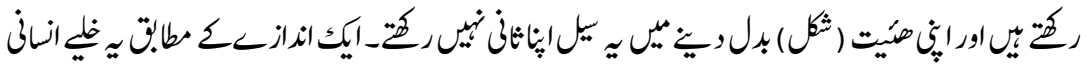

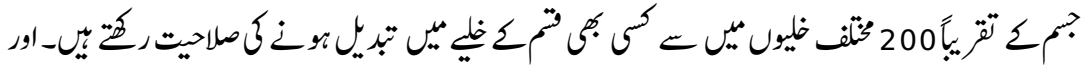

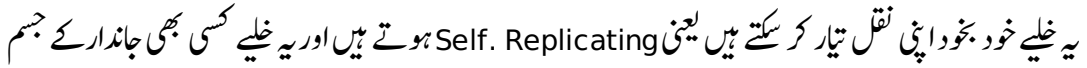

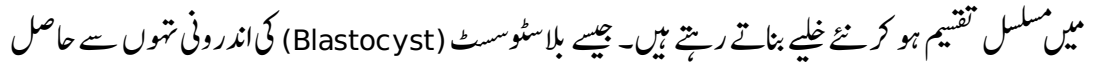

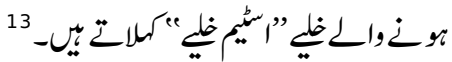

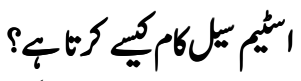

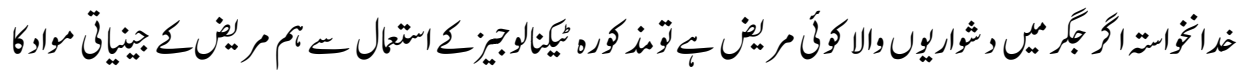

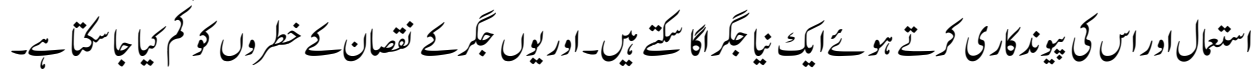

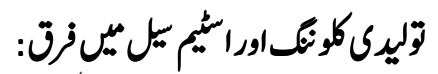

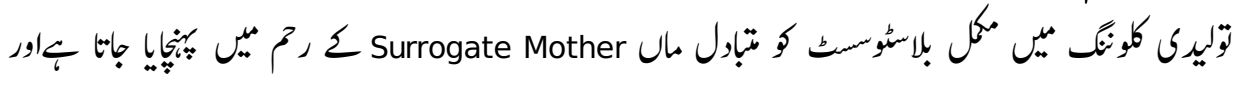




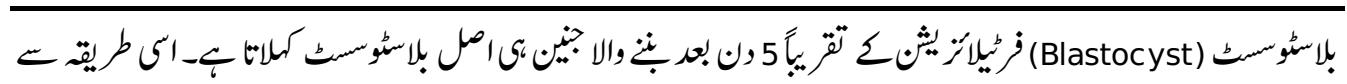

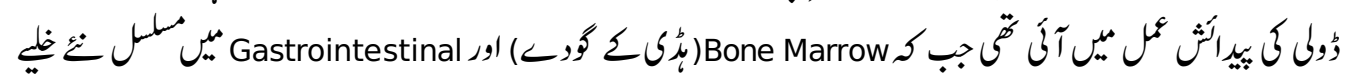

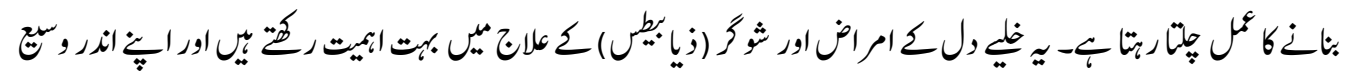

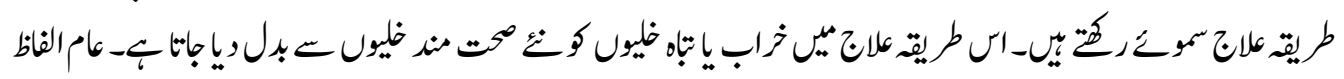

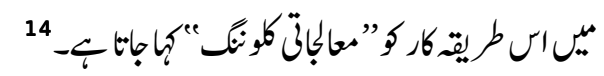

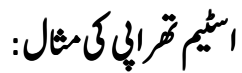

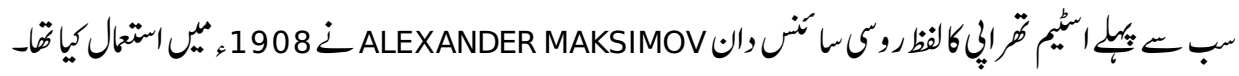

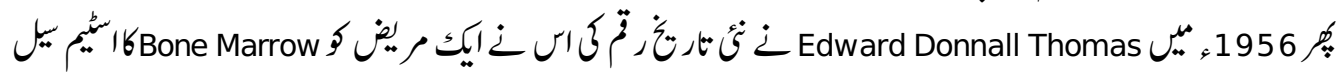

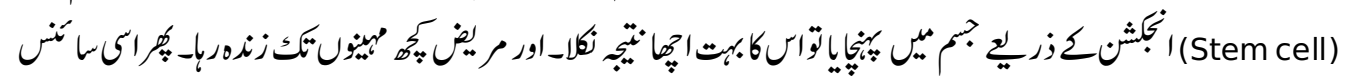

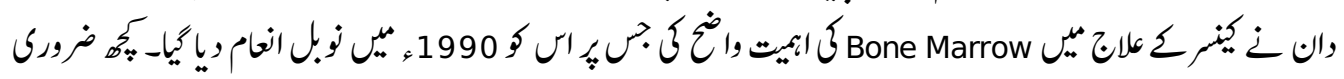
تبي ليول

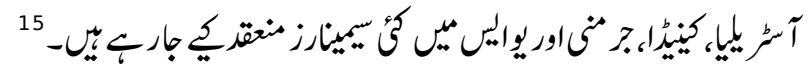

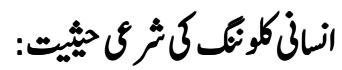

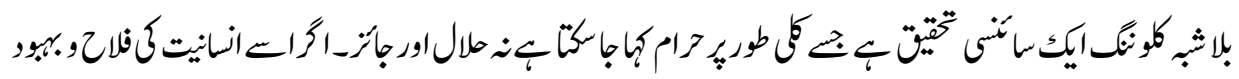

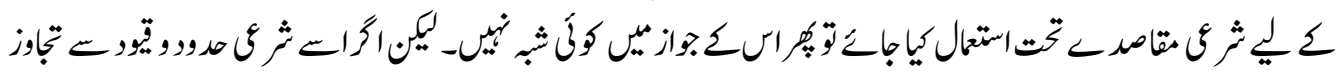

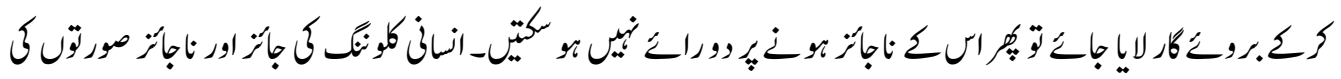

\section{وضاحتورجزيل

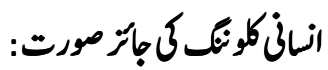

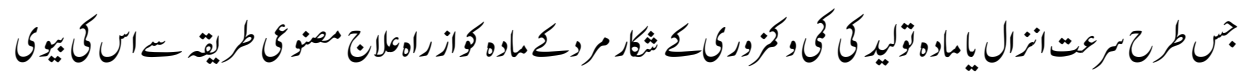

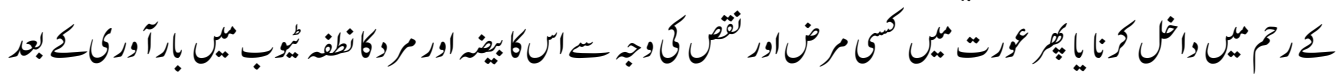

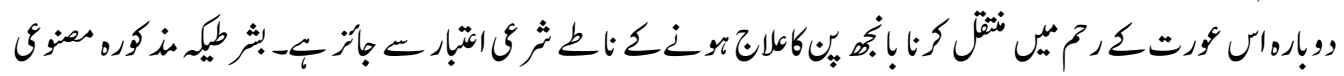

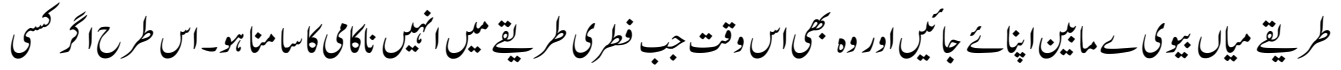

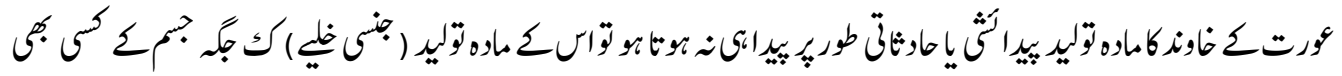

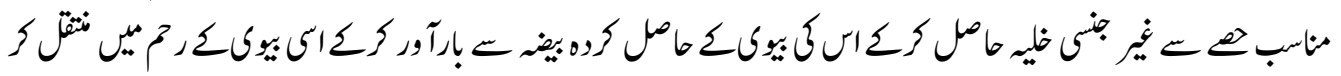

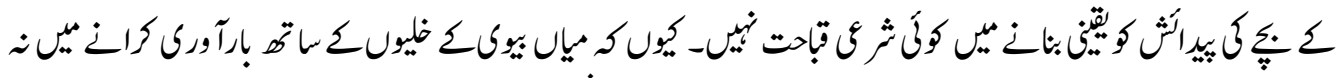

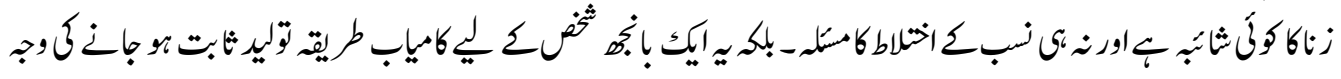

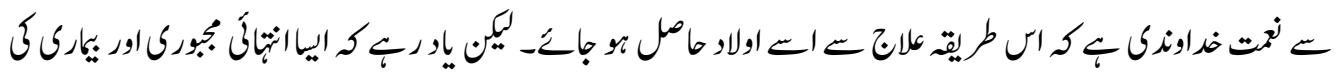

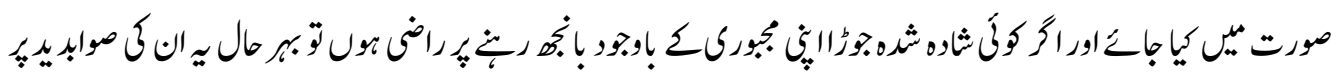




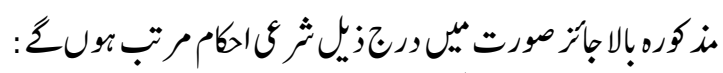

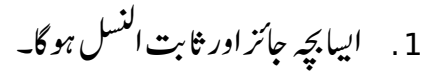

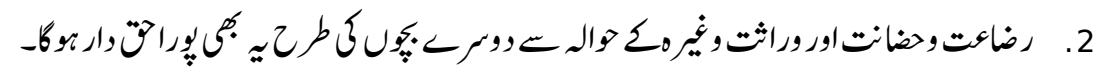

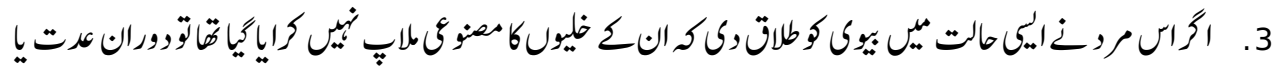

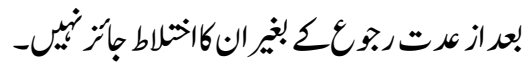

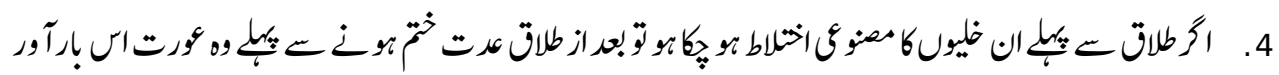

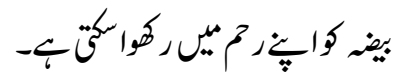

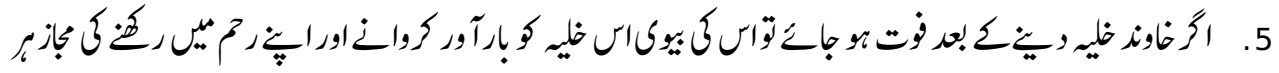

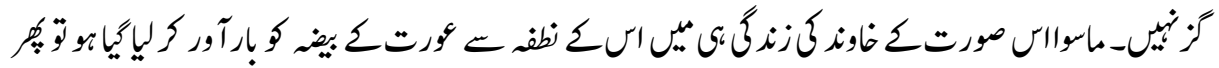

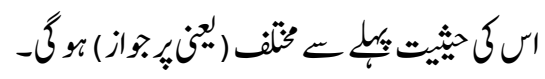

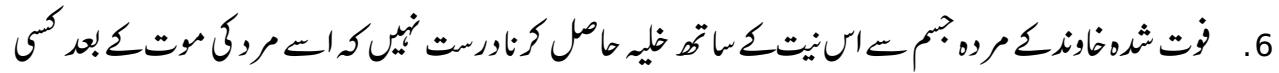

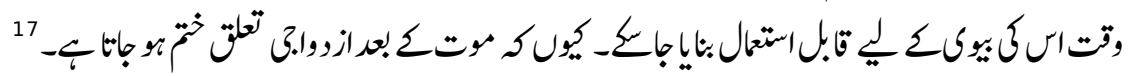

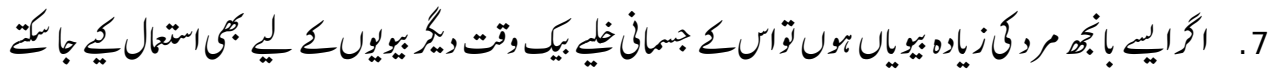

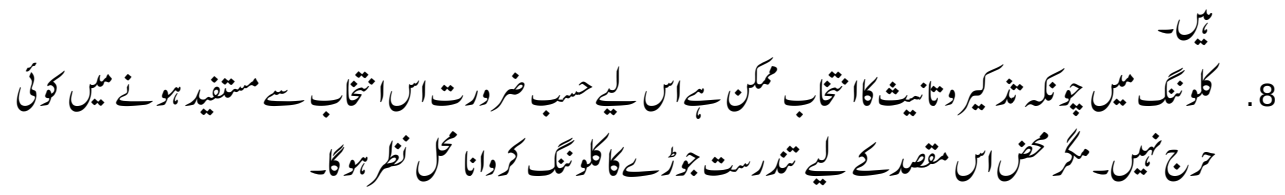

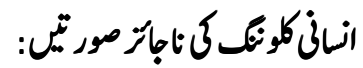

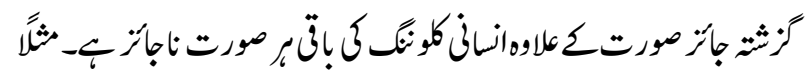

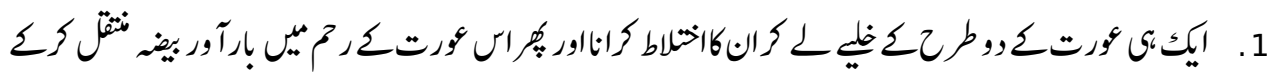

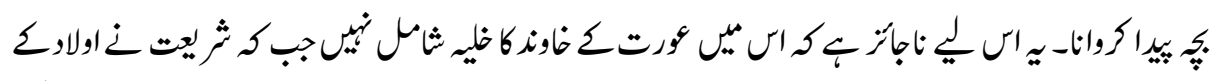

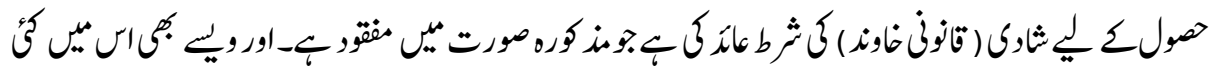

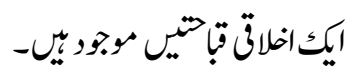

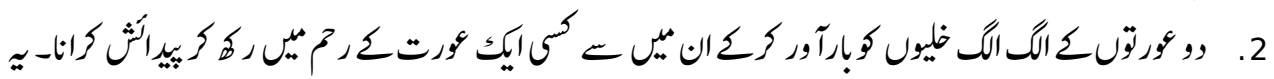

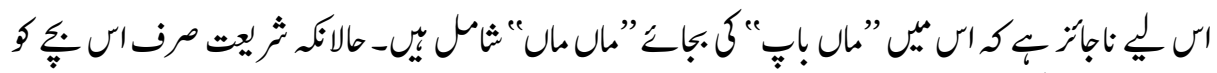

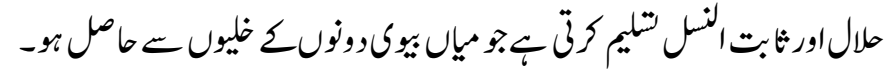

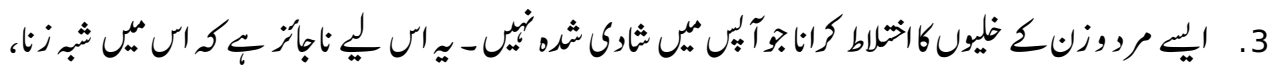

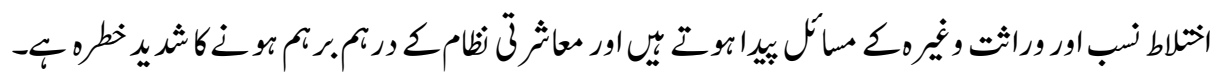




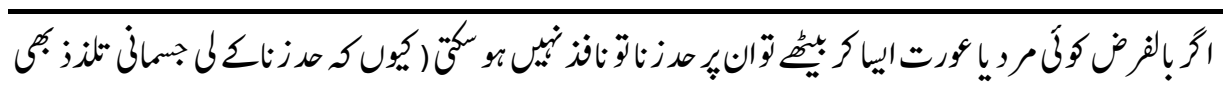

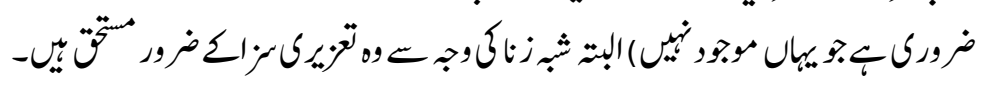

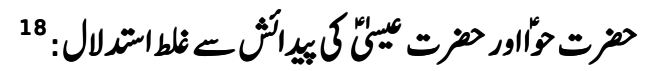

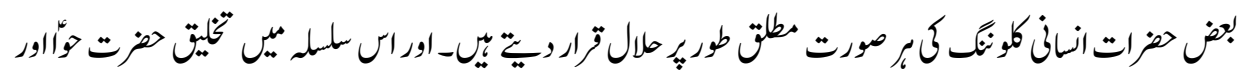

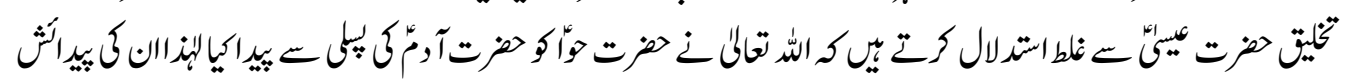

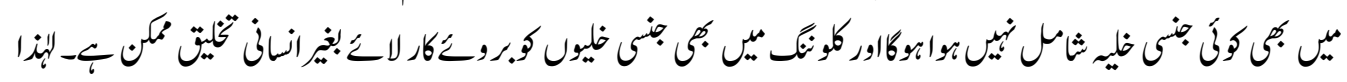

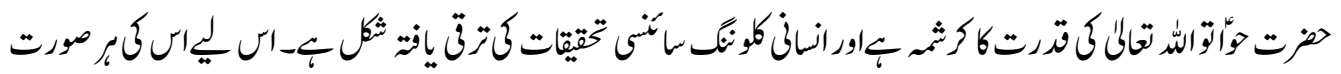

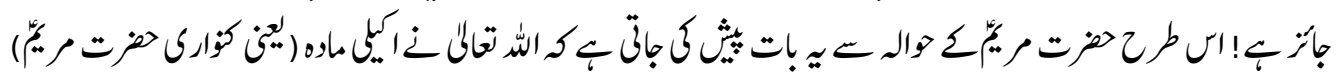

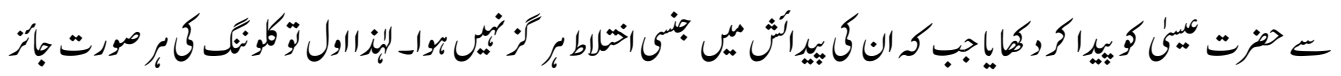

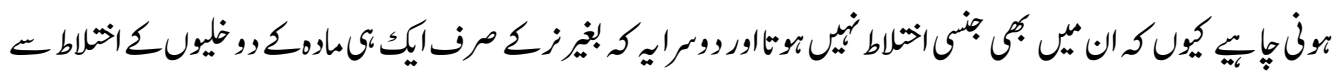

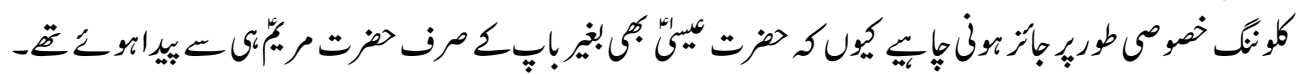

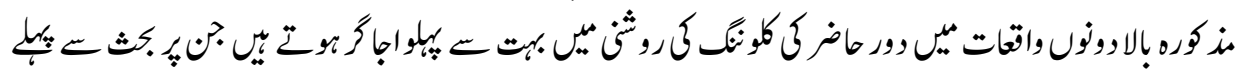

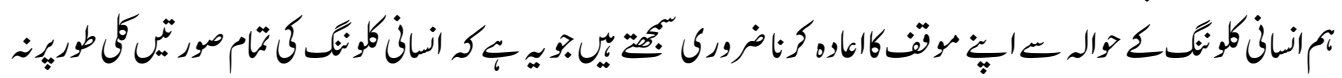

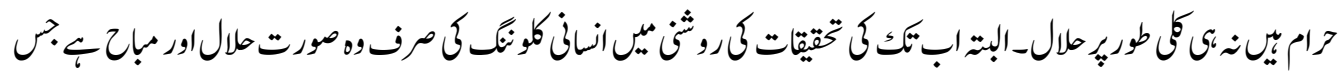

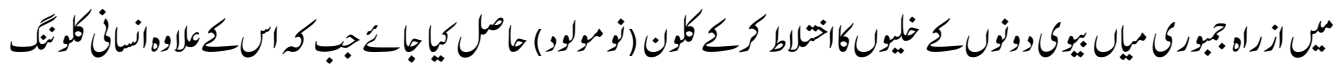

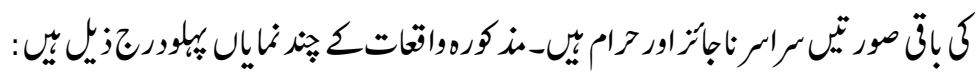

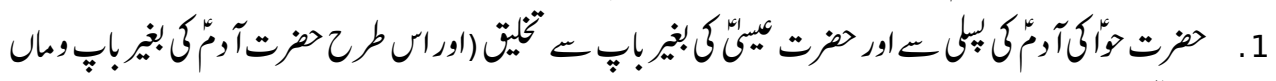

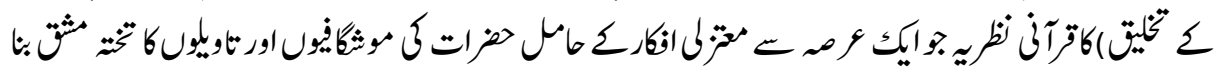

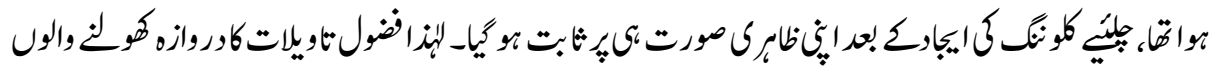

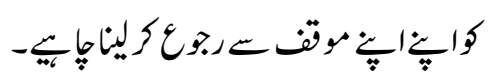

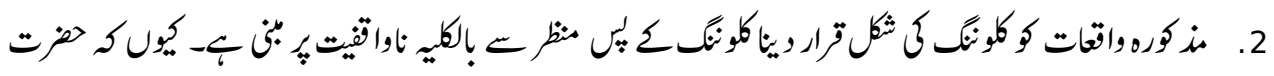

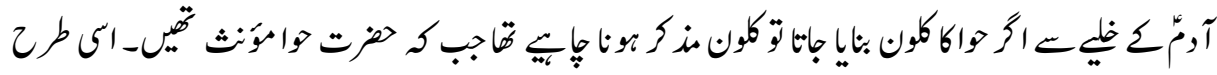

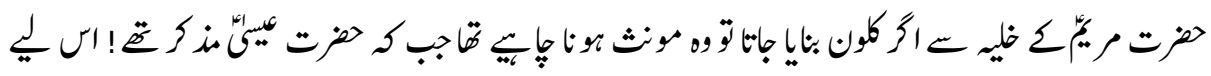

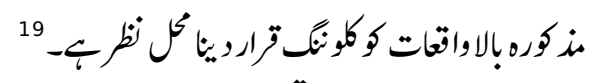

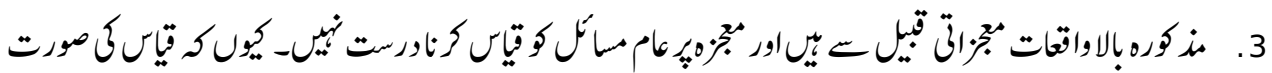

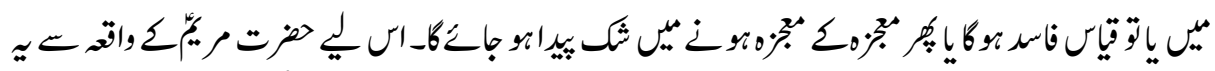

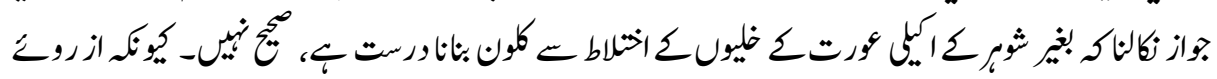

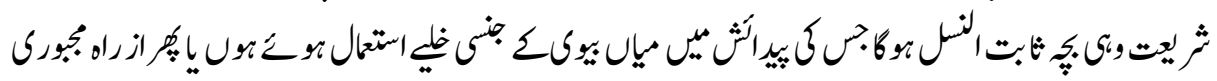




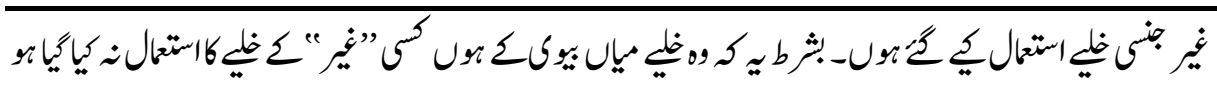

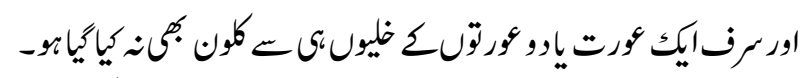

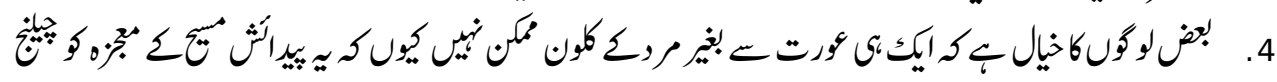

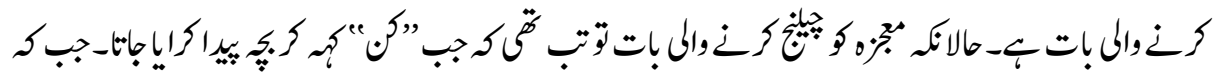

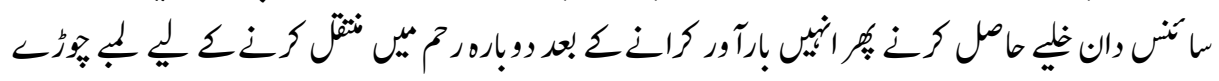

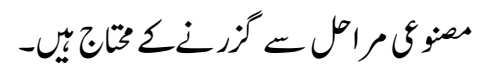

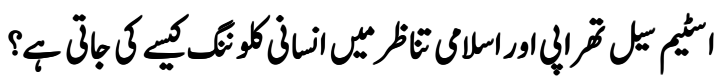

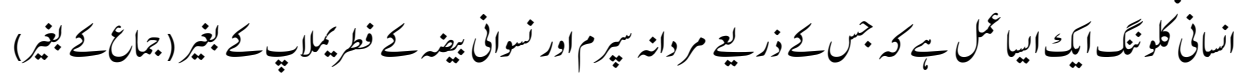

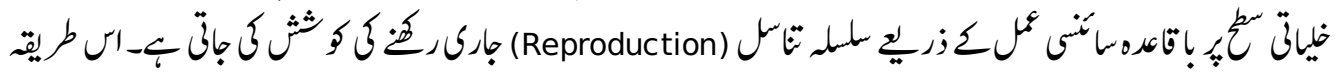

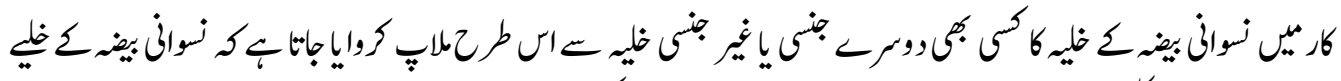

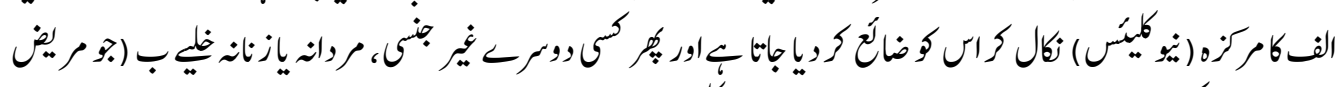

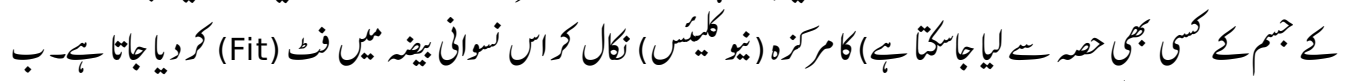

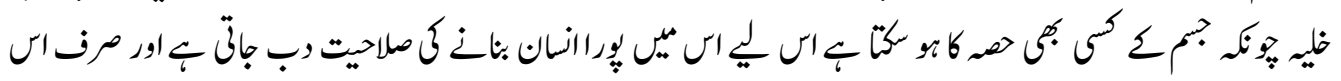

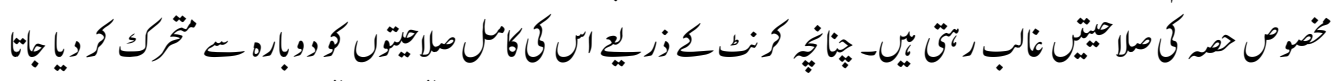

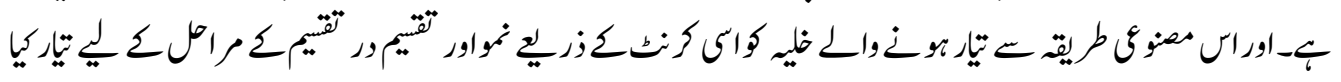

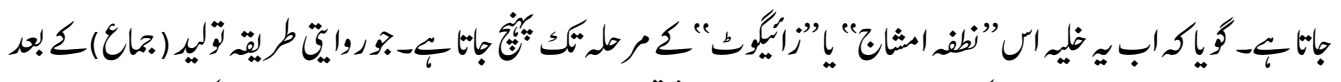

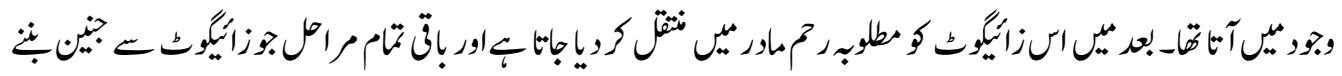

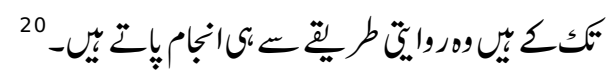

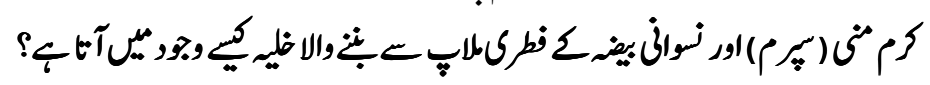

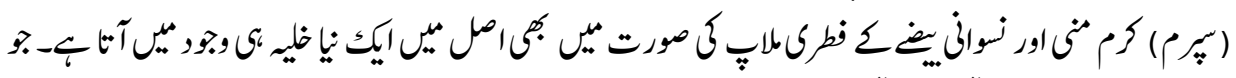

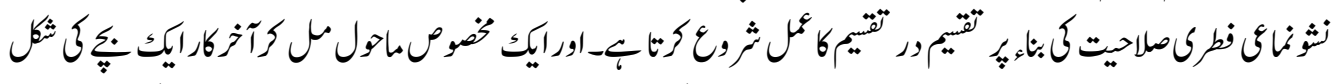

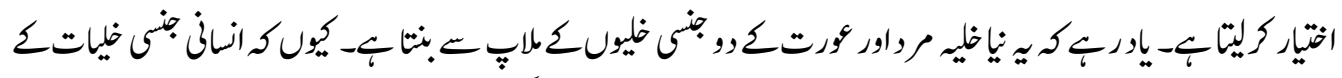

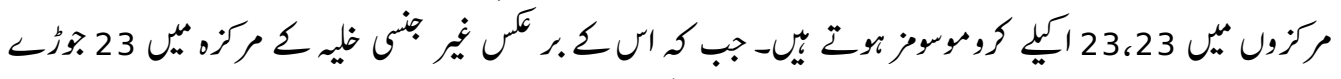

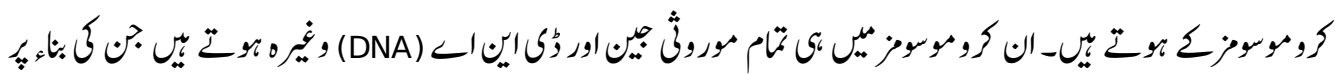

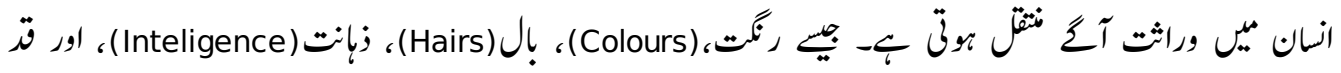
(Hight)

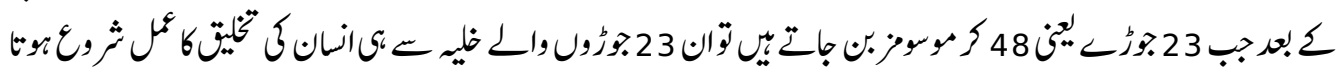




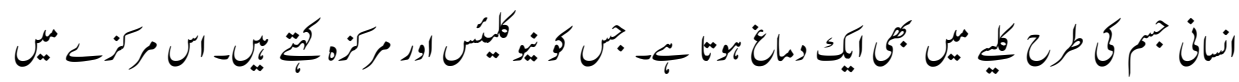

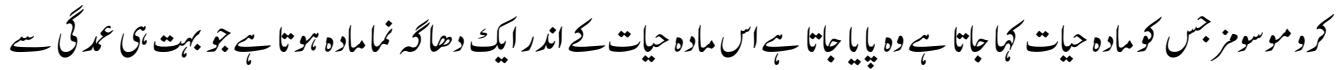

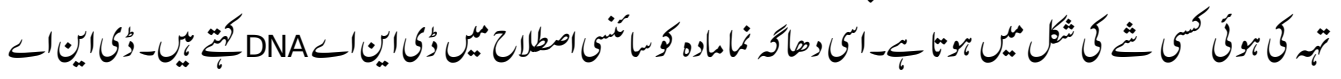
LDNA

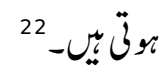

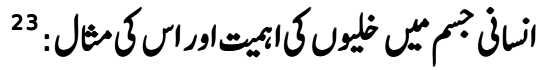

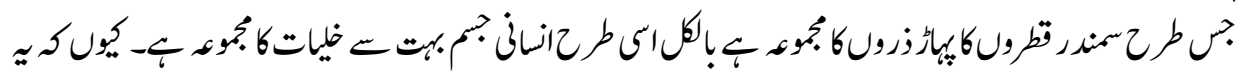

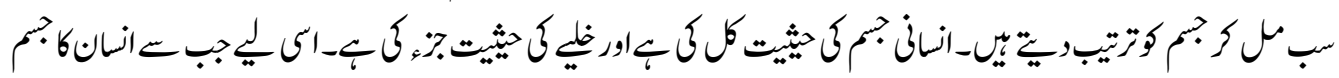

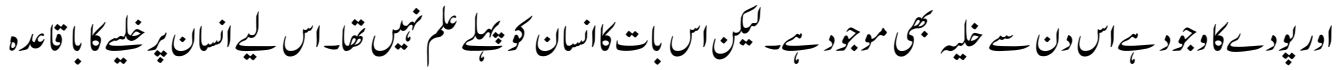

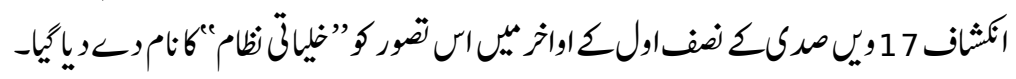

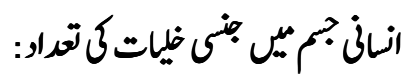

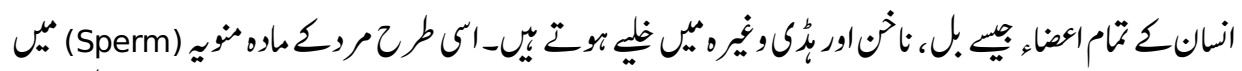

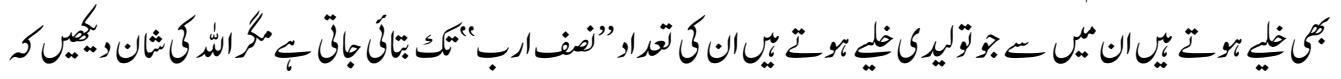

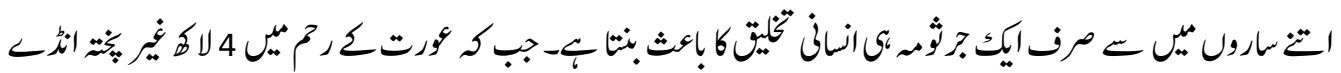

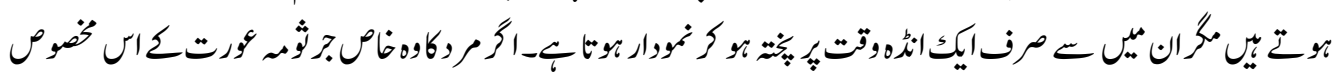

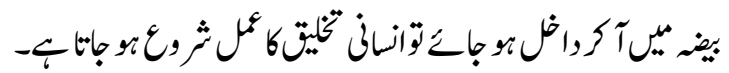

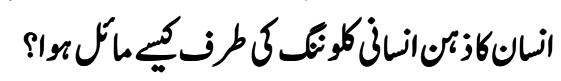

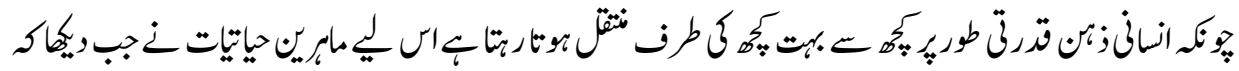

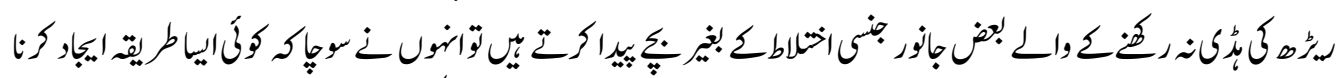

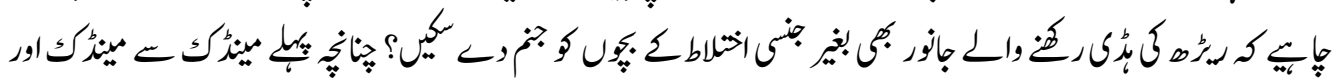

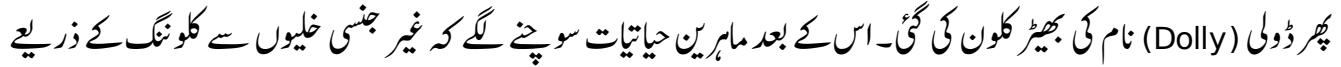

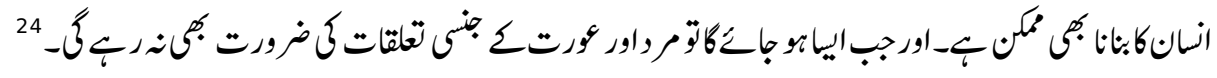

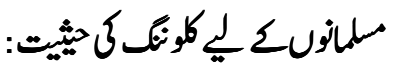

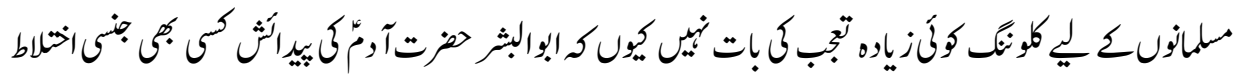

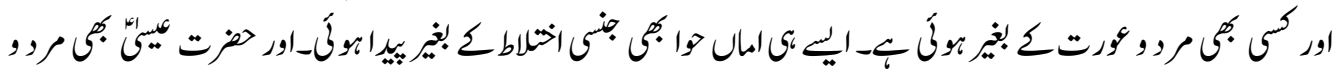

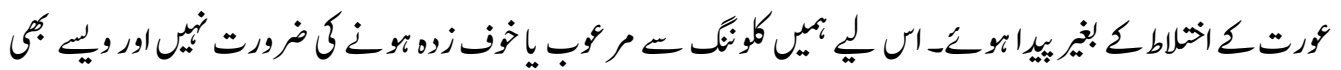

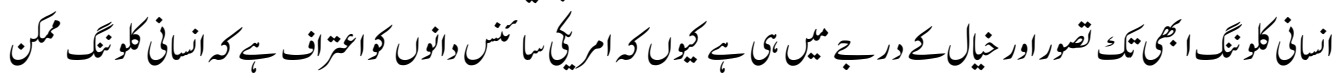




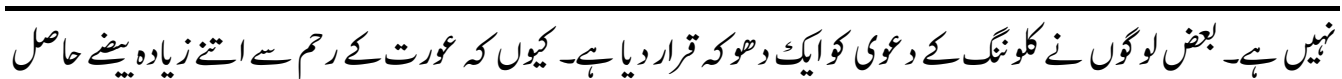

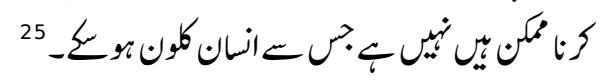

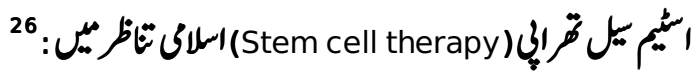

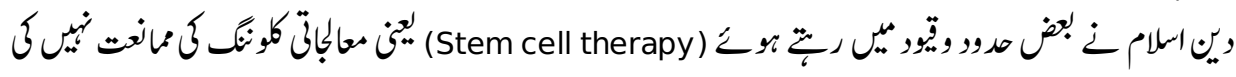

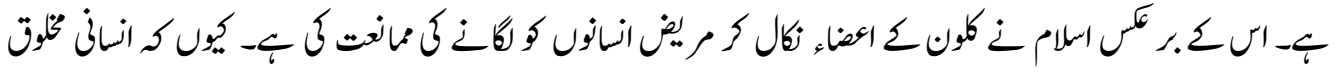

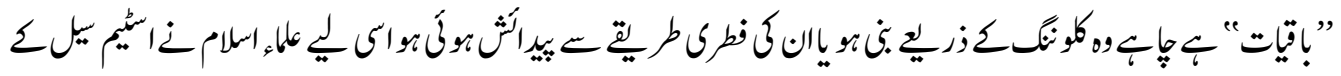

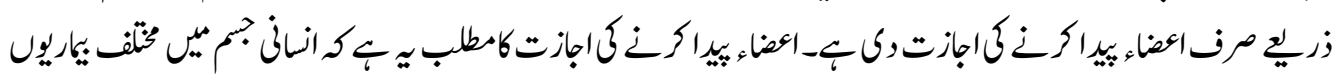

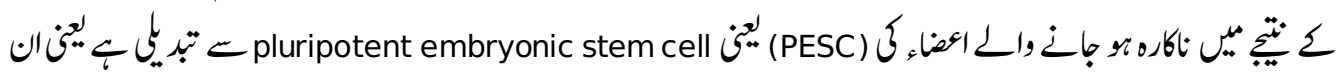

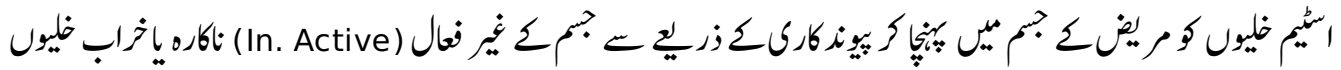

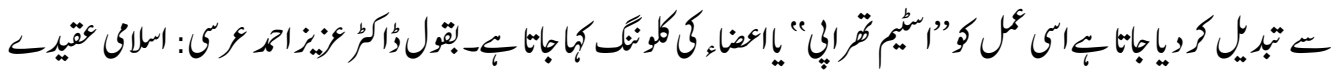

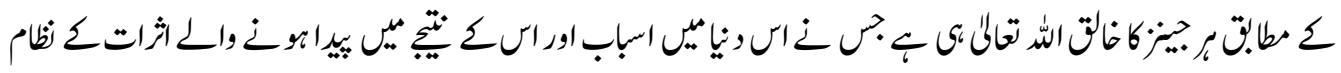

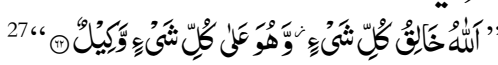

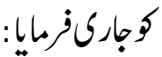

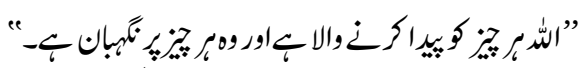

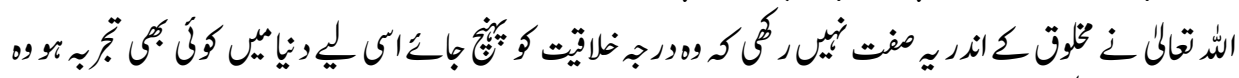

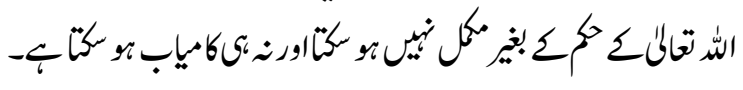
مثال:

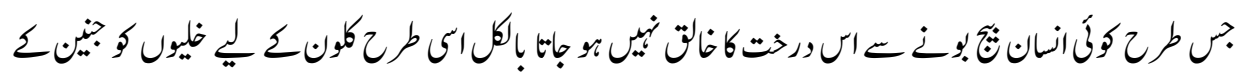

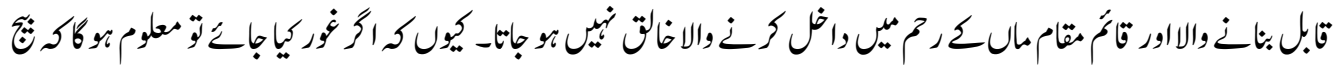

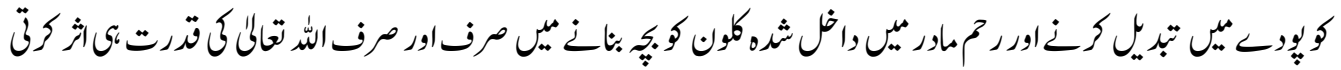

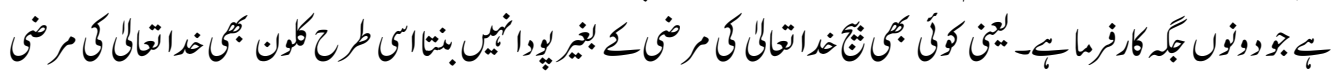

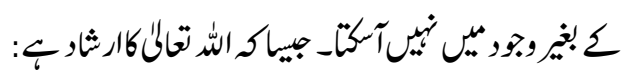

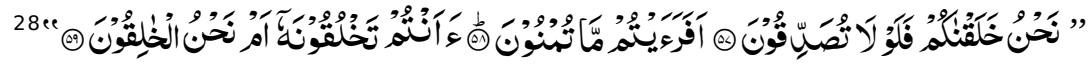

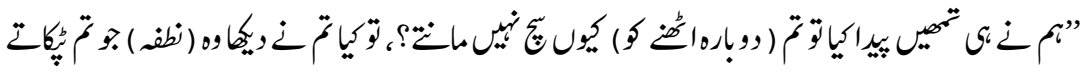

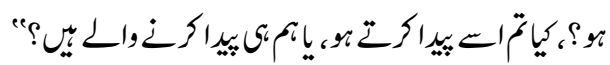

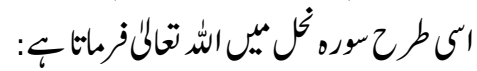

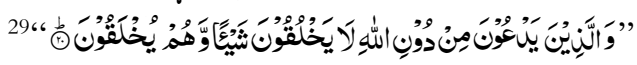

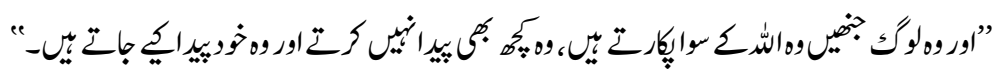




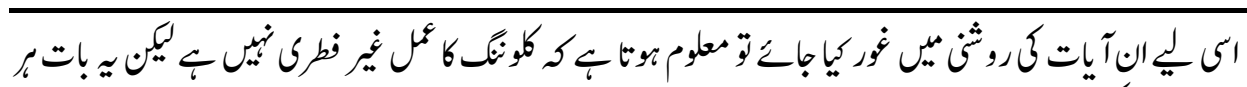

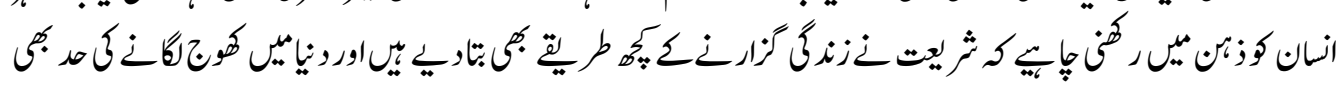

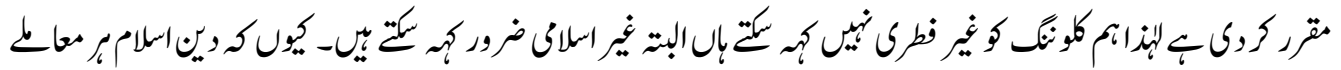

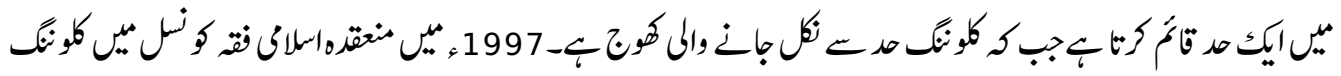

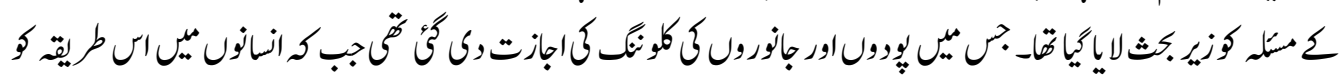

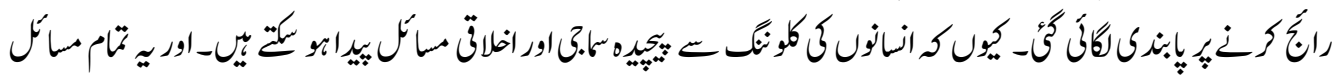

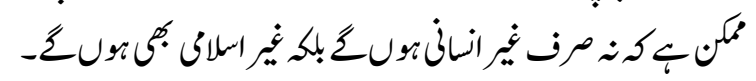

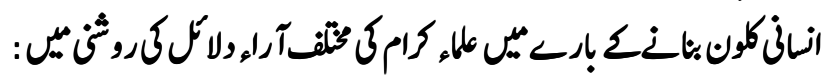

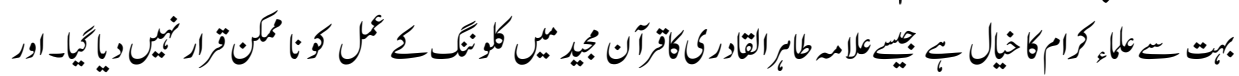

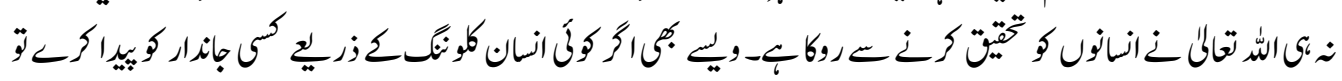

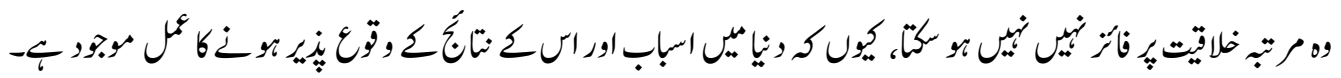

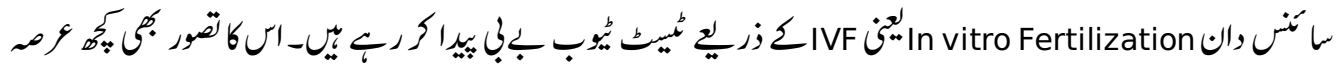

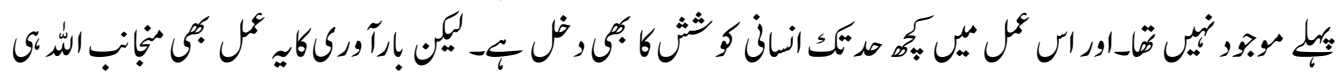

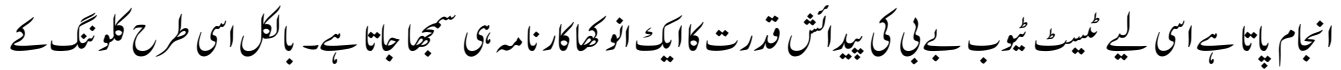

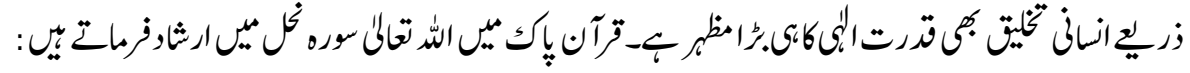

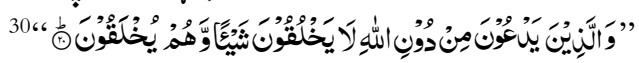

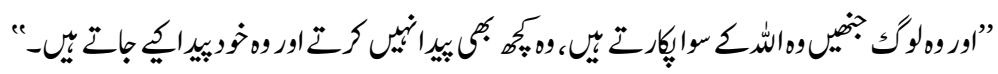

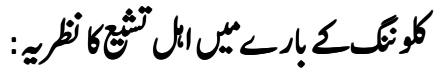

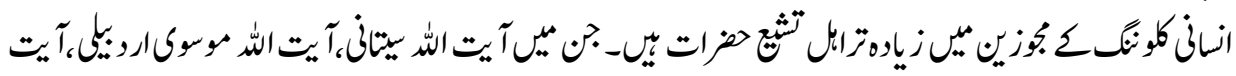

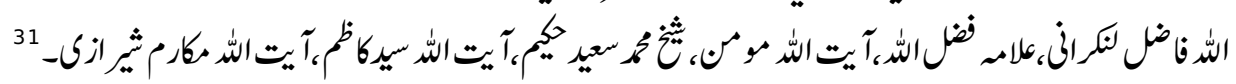

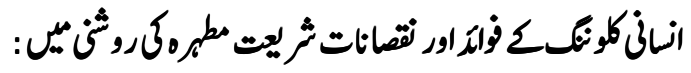

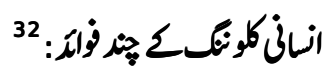

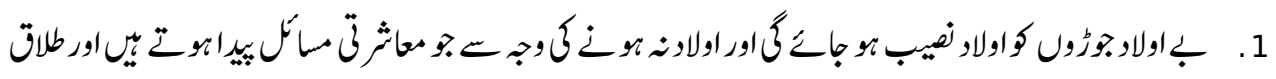

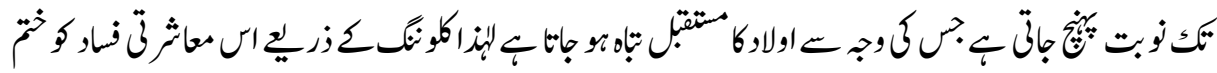

$$
\text { كانس }
$$

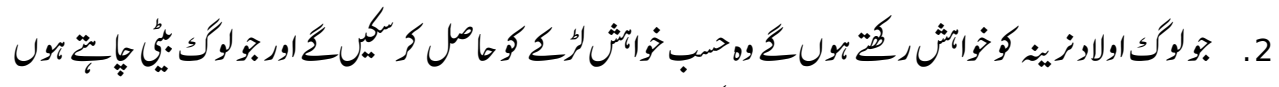

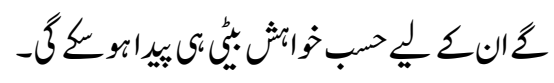

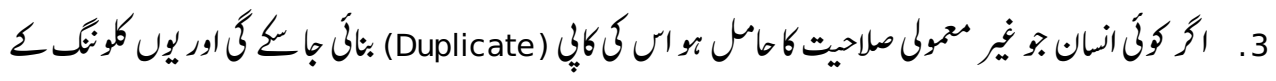




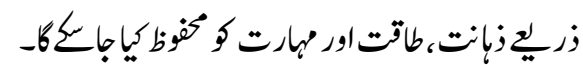

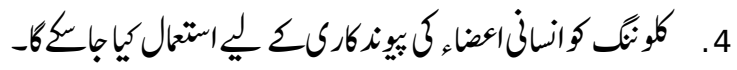

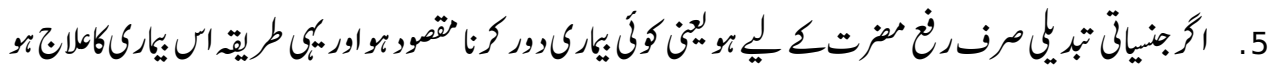

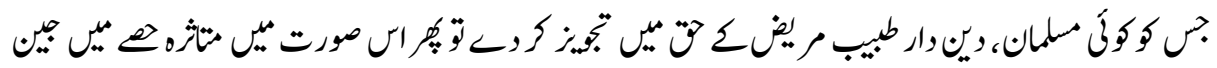

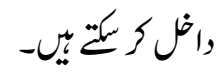

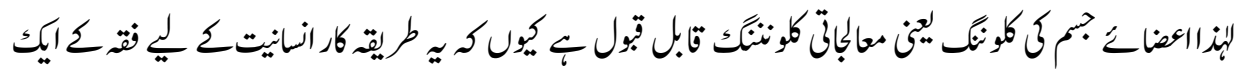

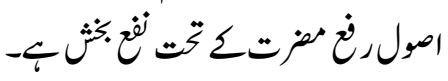

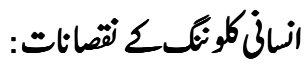

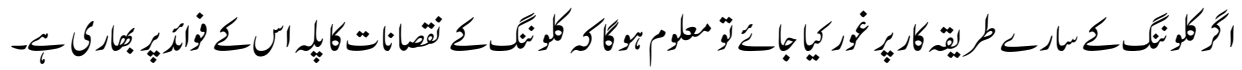

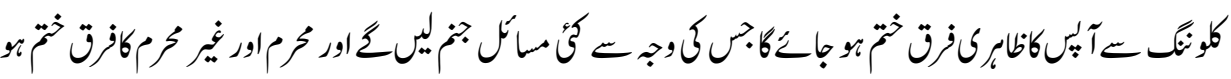

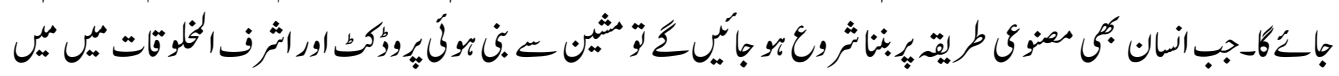

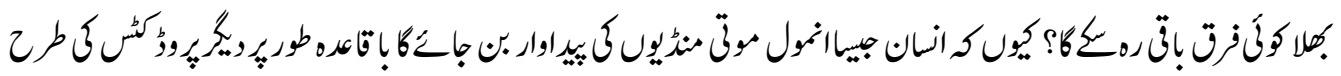

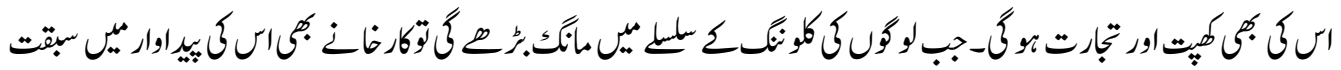

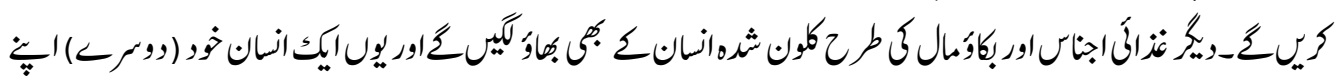

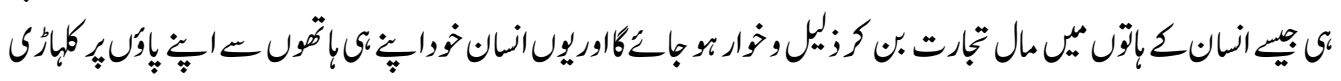

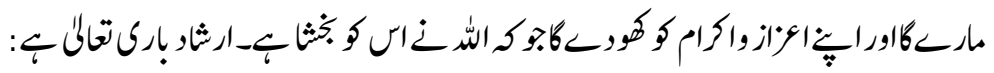

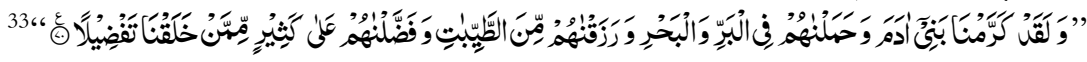

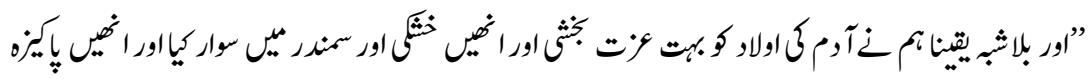

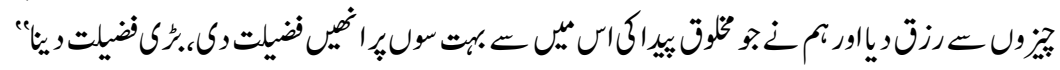

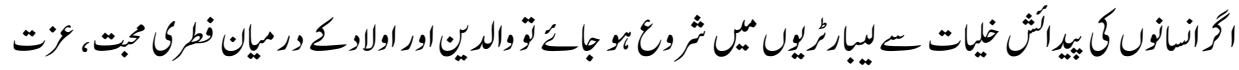

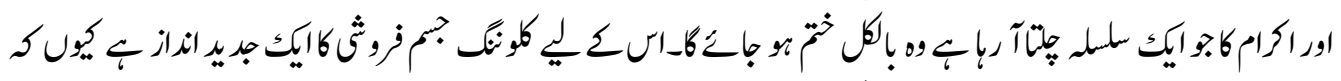

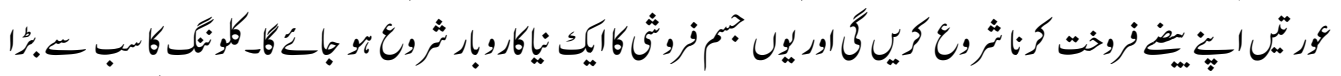

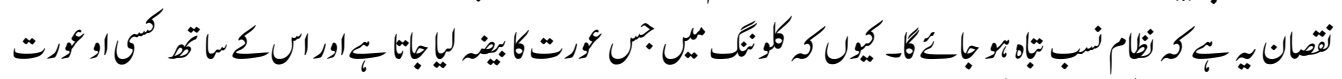

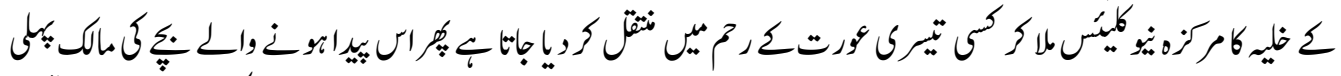

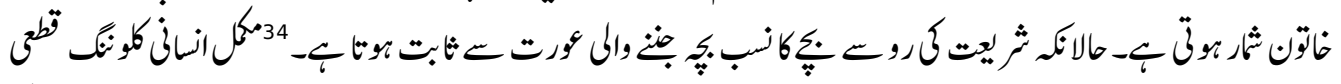

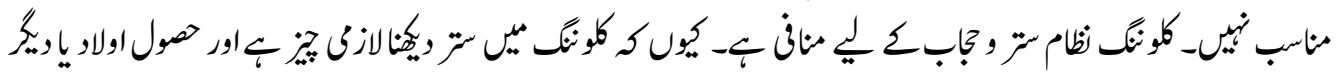

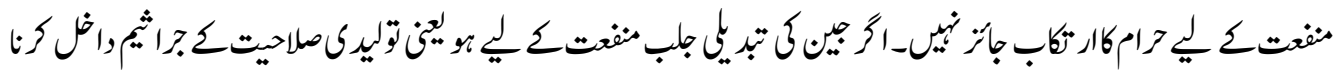




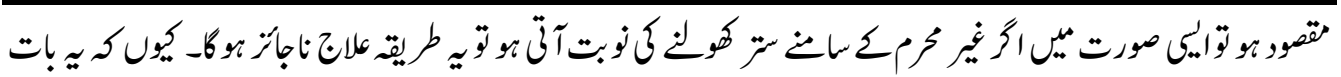

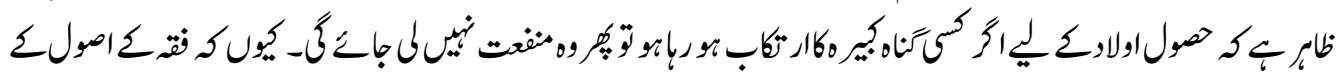

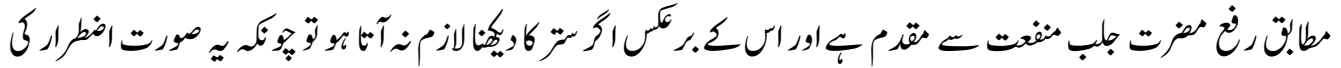

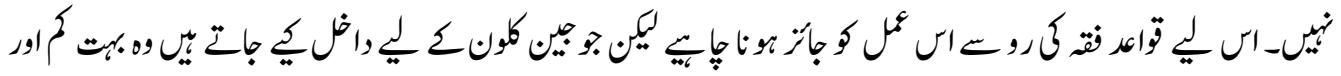

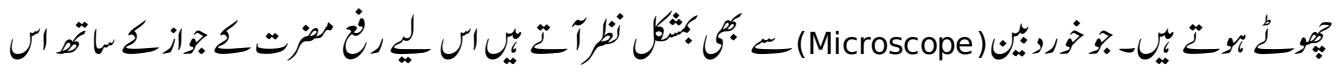

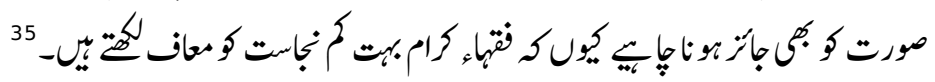

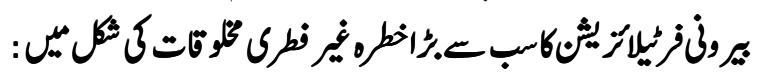

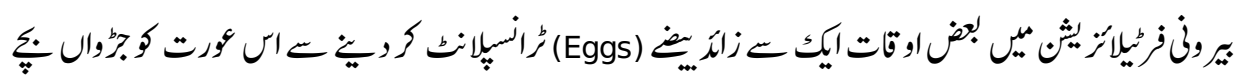

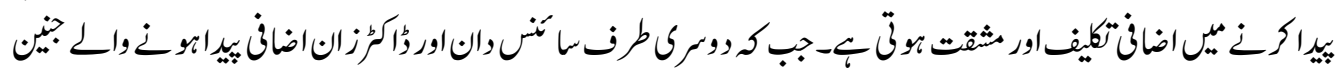

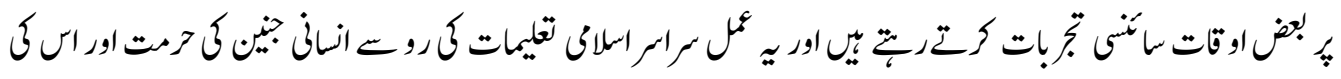

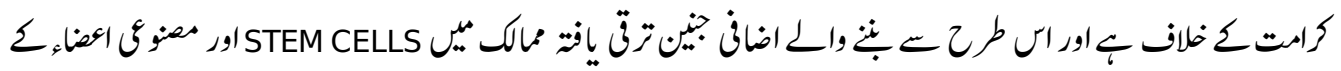

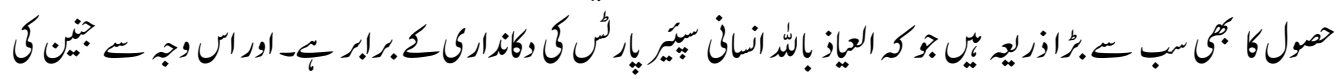

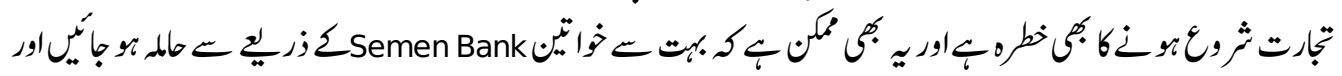

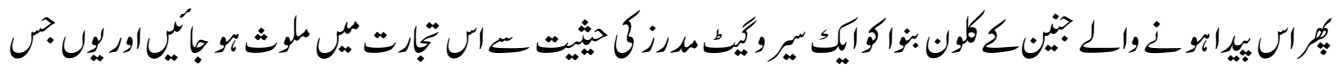

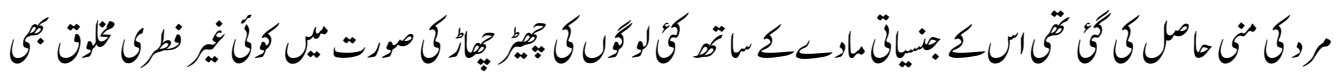

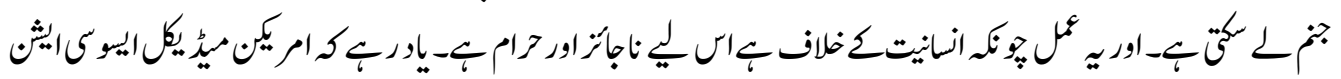

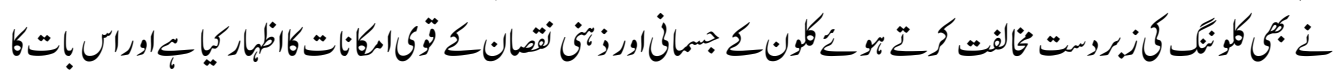

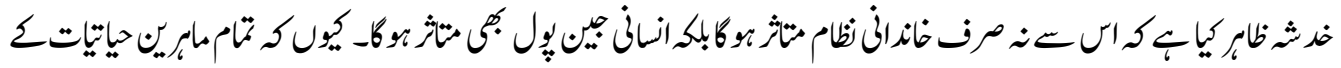

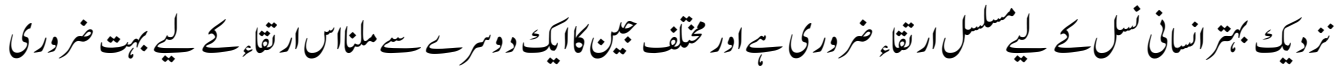

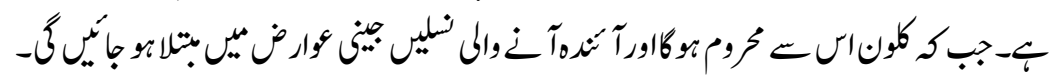

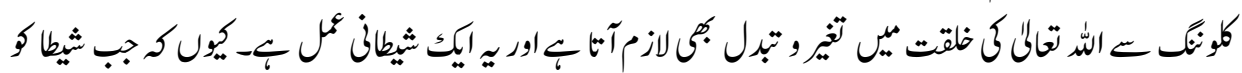

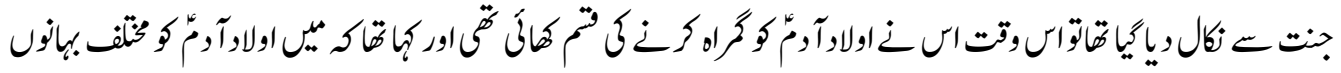

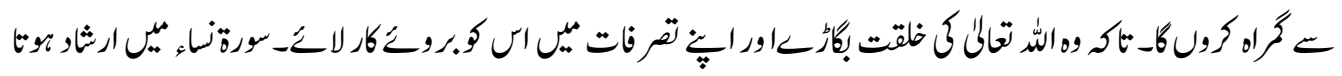

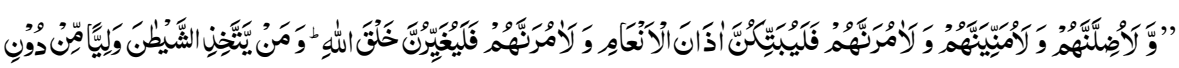

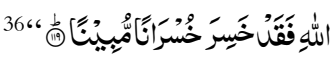

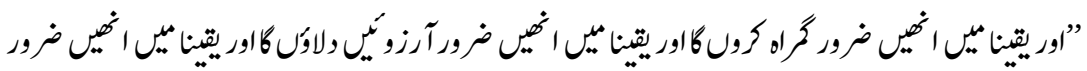

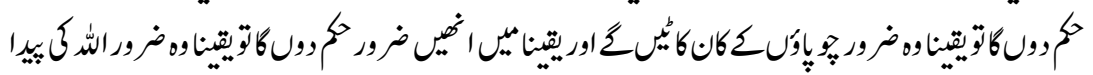

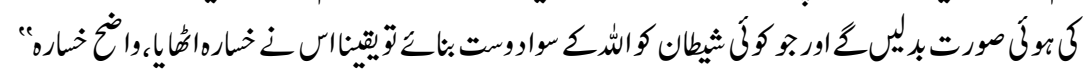




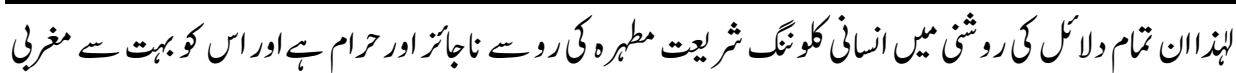

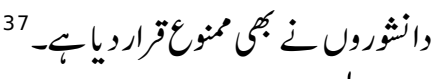

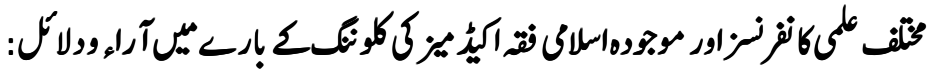

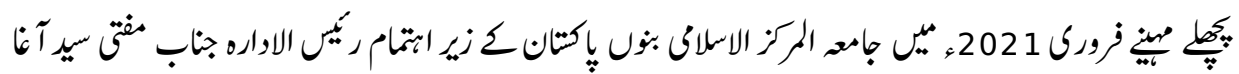

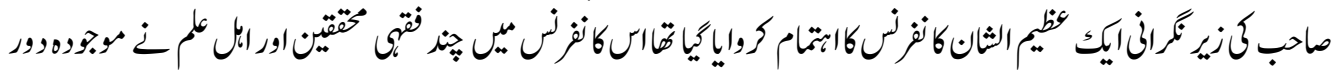

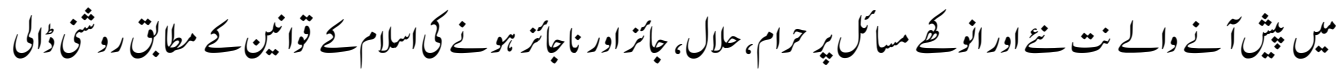

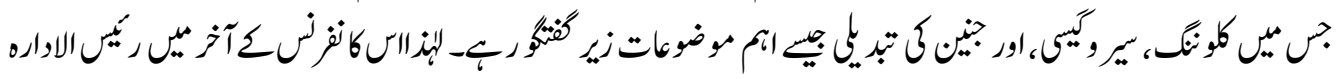

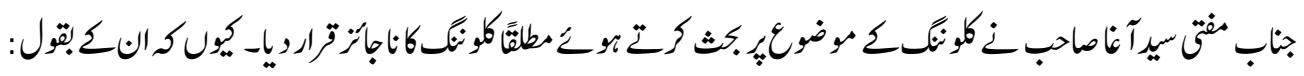

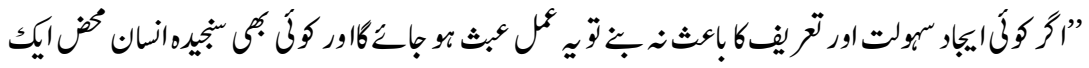

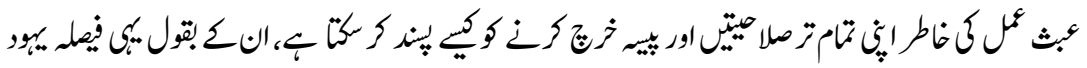


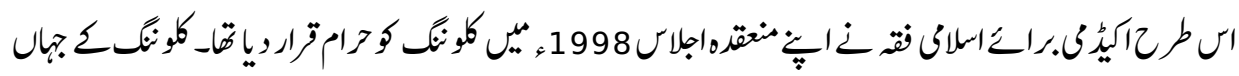

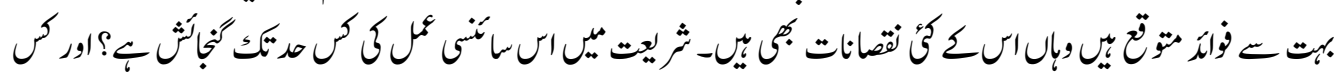

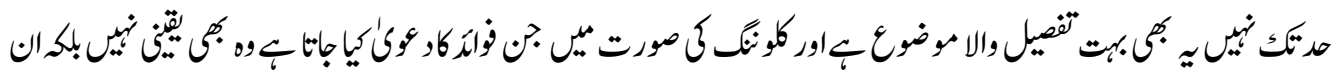

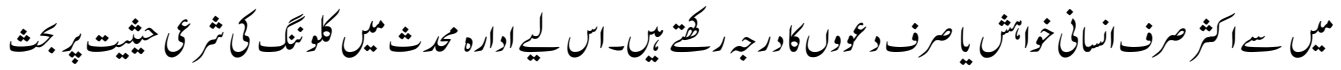

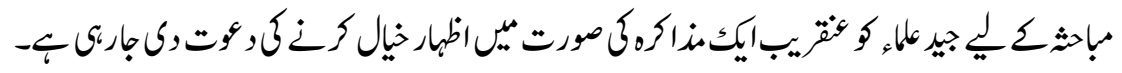

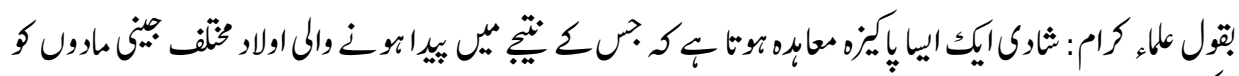

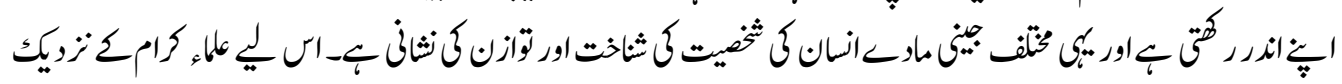

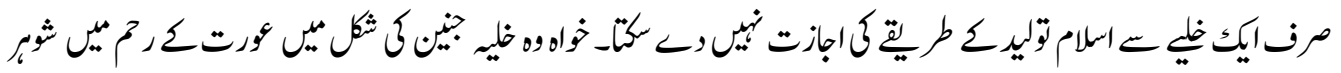

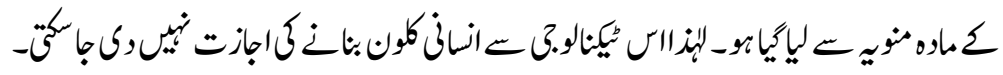

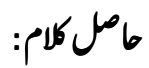

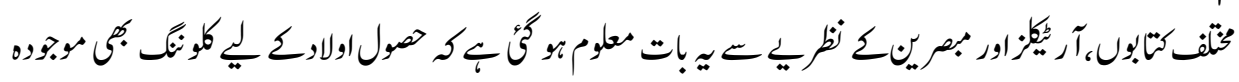

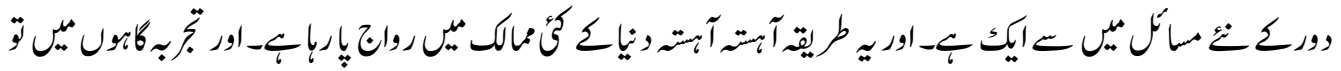

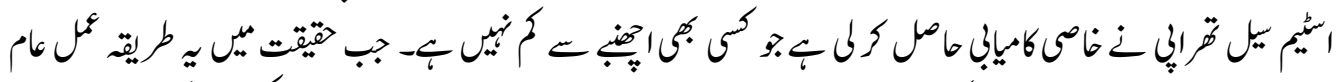

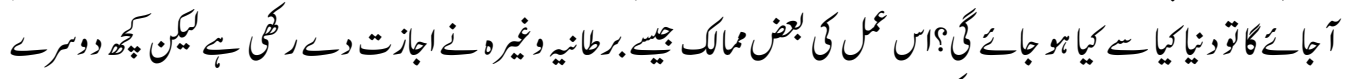

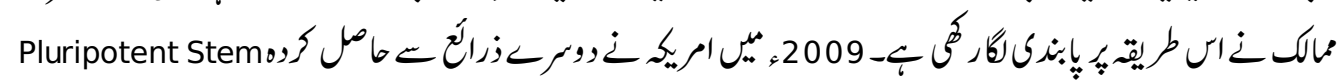

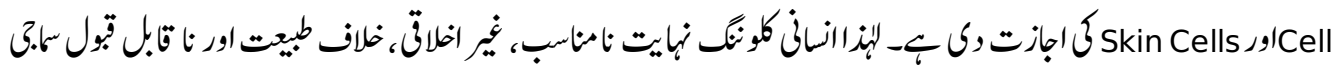

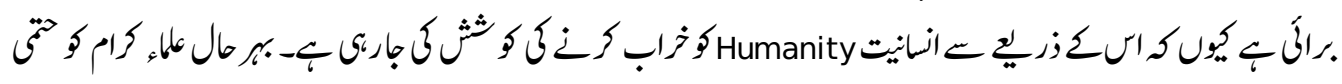




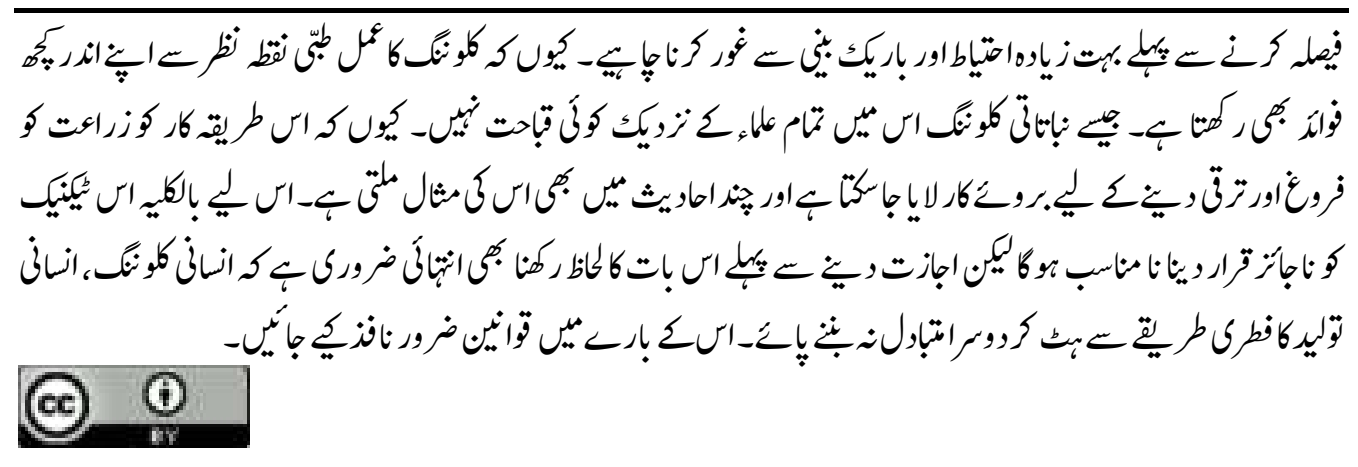

This work is licensed under a Creative Commons Attribution 4. 0 International License.

\section{حاثّى واله جات}

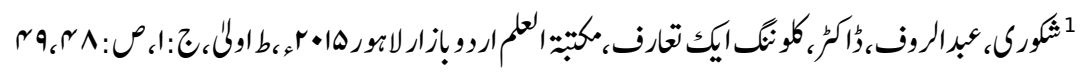

Shakūrī, 'bd al-Ra,ūf, Cloning aik Ta'āruf, (Maktabat al-'Im, Urdū Bazār, Lāhūre, 2015ac, $1^{\text {st }}$ edition), Vol:01,pp:48-49

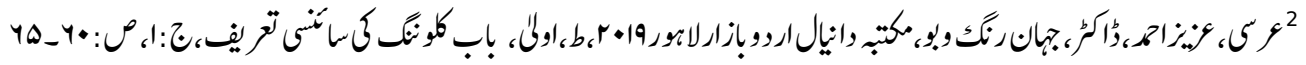

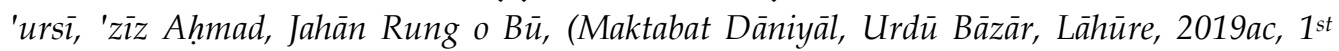
edition), Vol:01,pp:60-65

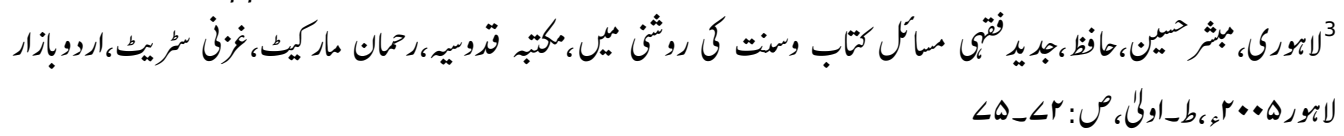

Mubashar Husain, Jadìd Fiqhī Masā,l Kitāb wa Sunnat kī Rowshnī mai, (Maktabat Quddūsiyat, Raḥmān Mārkìt, Ghaznī Street, Urdū Bāzār, Lāhūre, 2005ac, 1'st Edition), pp:7275

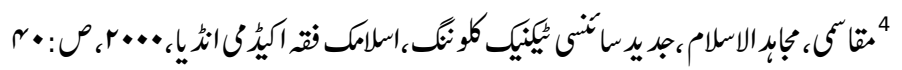

Maqāsmī, Mujāhid al-Islām, Jadīd Sā,nsī Tyknīk Kaloning, (Islāmic Fiqh Acedemī, India,2000), $p: 40$

${ }^{5}$ Bertero, A., Brown, S., E Vallier, L. (2017). Methods of Cloning. Basic Science Methods for Clinical Researchers, 19-39. https://doi.org/10.1016/B978-0-12-803077-6.00002-3

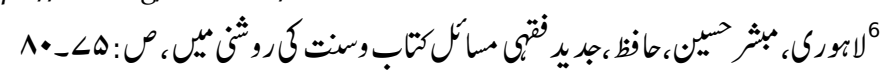

Mubashar Husain, Jadìd Fiqhī Masā,l Kitāb wa Sunnat kī Rowshnī mai,pp:75-80

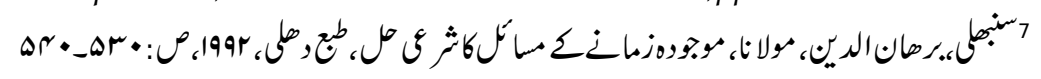

Sunblì, Burhān al-Dìn, Mwjūdat Zamāny ky Msā,l kā Shar'ì Hal, (Dehlì,1992ac), pp:530-540

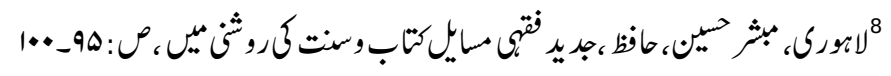

Mubashar Husain, Jadìd Fiqhī Masā,l Kitāb wa Sunnat kī Rowshnī mai,pp:95-100

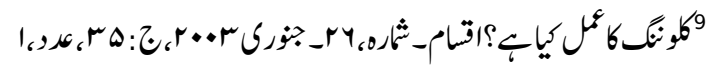

Kalūning kā 'mal kiyā hay?, Aqsām, Issue, 26, Jan-2003, Vol:35, 'dad:1

$$
\text { 10 لبقه :255 }
$$




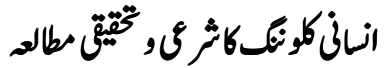

Al-Baqarat, Verse:255

11Nasr-Esfahani, Mohammad Hossein, Khadijeh Ahmad-Khanbeigi, and Ali Hasannia. 2021. "Qur'anic Views on Human Cloning (I): Doctrinal andTheological Evidences." International Journal of Fertility \& Sterility 15 (1): 73. https://doi.org/10.22074/IJFS.2020.134415.

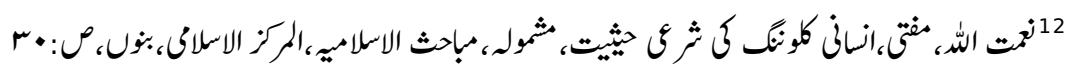

Ni'mat Allah, Muftì, Insānì Kalūning kī Shar'ì Hythiyat, (Mashmūlat Mabāhith al-Islāmiyat, Al-Markaz al-Islāmī, Banū), p:30

${ }^{13}$ Larijani, Bagher, and F. Zahedi. 2004. "Islamic Perspective on Human Cloning and Stem Cell Research." Transplantation Proceedings $36 \quad$ (10): 3188-89. https://doi.org/10.1016/j.transproceed.2004.10.076.

${ }^{14}$ Ibid

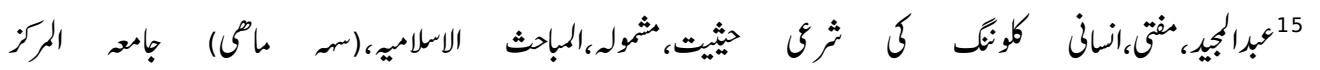

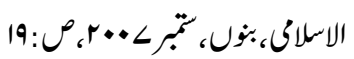

'bd al-Majīd, Muftì, Insānī Kalūning kī Shar'ì Hythiyat, (Mashmūlat Mabāhith al-Islāmiyat, Al-Markaz al-Islāmī, Banū,Sep-2007),p:19

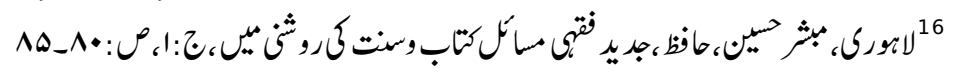

Mubashar Husain, Jadìd Fiqhī Masā,l Kitāb wa Sunnat kī Rowshnī mai,Vol:01,pp:80-85

$$
\text { 17 }
$$

Ibid

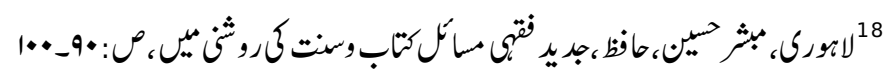

Mubashar Husain, Jadìd Fiqhī Masā,l Kitāb wa Sunnat kī Rowshnī mai,pp:90-100

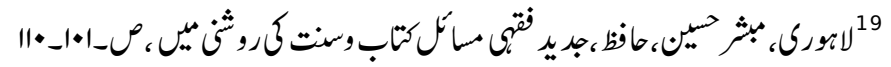

Mubashar Husain, Jadìd Fiqhī Masā,l Kitāb wa Sunnat kī Rowshnī mai,pp:101-110

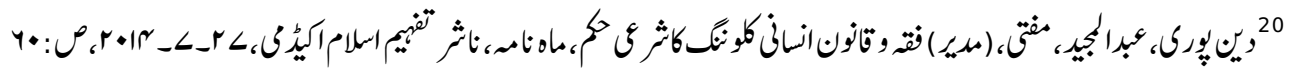

Deen pūrì, 'bd al-Majìd,(Editor), Figh wa Qānūn Insānì Kalūning kā Shar'ì Hukam, Monthly, (Tafhìm Islām Academy, 27-07-2014ac), p:60

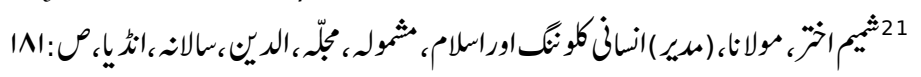

Shamìm Akhtar, Mowlānā, (Editor), Insānī Kalūning aur Islām, (Mashmūla, Majallat, AlDin, Yearly, India), p:181

${ }^{22}$ Askari,Ahmad Hassan,DR,A comprehensive book of gynaecology, What is DNA?,Jadid Maktaba Daniyal,Lahore2018, V1, Pg 410

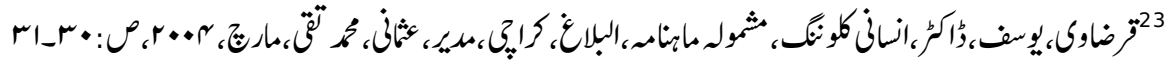

Qarḍāwī Yoūsaf, Insānì Kalūning, (Mashmūla Monthly Al-Balāgh Karāchī, (Editor: Muftī Taqì Uthmānī, March,2004ac), pp:30-31

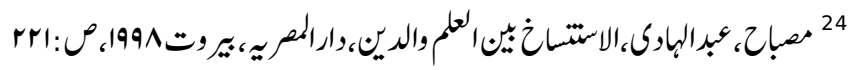

Abdul Hadi Misbah, Al Istskha bain ul Ilm wl Deen, Dar ul Misria, Barut, 1998, P:221 


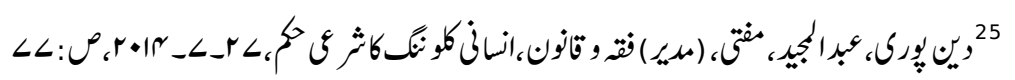

Deen pūrì, 'bd al-Majīd,(Editor), Fiqh wa Qānūn Insānì Kalūning kā Shar'ì Hukam, Monthly, (Tafhìm Islām Academy, 27-07-2014ac), p:77

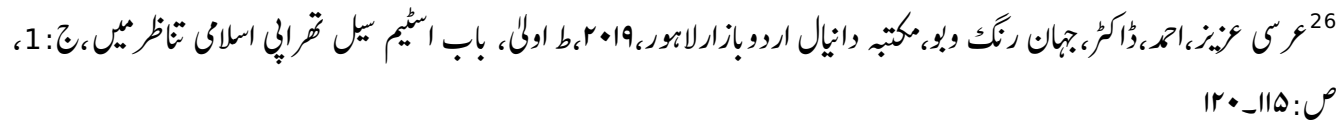
'ursī, 'zìz Aḥmad, Jahān Rung o Bū, (Maktabat Dāniyāl, Urdū Bāzār, Lāhūre, 2019ac, $1^{\text {st }}$ edition), Vol:01,pp:115-120

$$
\text { 4r: }: j^{27}
$$

Zumar, Verse: 62

$$
\Delta 9 \_\Delta<: \text { : }
$$

Al-Wāq'at, Verse: 57-59

$$
r \cdot: \text { r }^{29}
$$

Al-Nahl, Verse:20

$$
r \cdot: \underbrace{30}
$$

Al-Nahl, Verse:20

${ }^{31}$ Human cloning: ethical issues. UNESCO; 2004; 7-8. Available from: http://www.unescochair-bioethics.org/?mbt_book=humancloning-ethical-issues (9 May 2019).

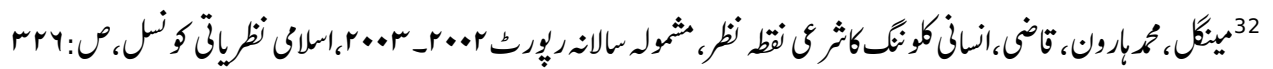

Mayngal, Muḥammad Hārūn, Qāẹ̄i, Insānì Kalūning kā Shar'ì Nuqța Nazar, (Mashmūla Yearly Report, 2002-2003, Islāmī Nazriyātì Council), p:326

Al-Isrā, Verse: 70

$$
L \cdot: \underbrace{\prime \prime 23}
$$

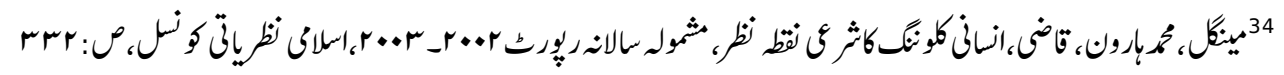

Mayngal, Muhammad Hārūn, Qāḍ̄, Insānī Kalūning kā Shar'ì Nuqța Naẓar, (Mashmūla Yearly Report, 2002-2003, Islāmī Nazriyātī Council), p:332

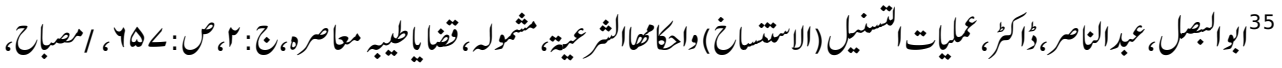

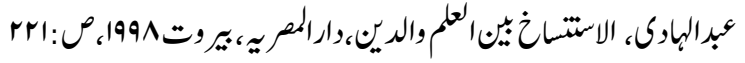

Abù al-Bașal, 'bd al-Nāṣir, 'mliyāt al-tansīl wa Ahkāmuhā al-Shar'iyat, (Mashmūlat, Qaḍayā Țayyibat Muāṣirat),Vol:02,p:657 / Mișbāhn, 'bd al-Hādì, Al-Istinsākh byn al-'lm wa al-dīn, (Dār al-Mișriyat, Berūit, 1998ac), p:221

$$
119: \text { : لنساء } 36
$$

Al-Nis̄a ${ }_{1,}$ Verse: 119

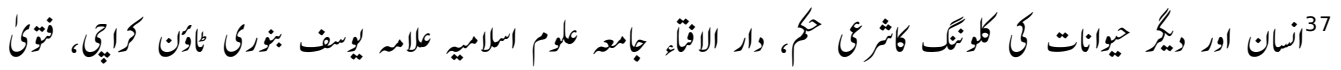

$$
\begin{aligned}
& \text { 144107200252: }
\end{aligned}
$$

Insān aur Dìgar Hywānāt kì Kalūning kā Shar'ì Hukum, Dār al-Iftā, Jāmeā 'lūm Islāmiyat 'llāmat Yoùsaf Binūrì Tāūn, Karāchì, Fatwā No.144107200252 


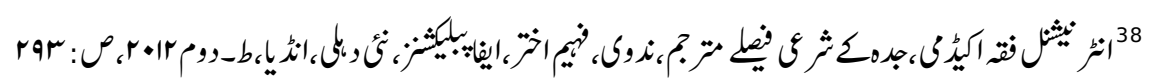

International Figh Academy, Jiddah kay Shar'ī Faisly, Translator: Nadwī Fahìm Akhtar, (Eîfā Publications, New Dehli, India, $2^{\text {nd }}$ Edition, 2012ac), p:293 